\title{
Muertes por sumersión. Revisión y actualización de un tema clásico de la medicina forense.
}

\author{
Deaths by Drowning. A classic topic in Forensic Medicine \\ revisited.
}

\section{JL. Romero Palanco}

\begin{abstract}
RESUMEN
La recuperación de un cadáver del agua plantea siempre múltiples y variadas cuestiones a las que no es posible encontrar respuesta adecuada en algunas ocasiones; y ello a pesar de la riqueza de signos que suelen ofrecer los cuadros de asfixia por sumersión.

En el presente trabajo se realiza una revisión crítica y actualización de las muertes por sumersión a la vista de los recientes conocimientos sobre las alteraciones fisiopatológicas inducidas por estos cuadros, poniendo especial interés en los casos de cuerpos recuperados del agua con "pulmones secos". Los hallazgos necrópsicos son objeto de revisión, así como los estudios histopatológicos e histoenzimáticos. Se realiza, asimismo, una amplia revisión de los exámenes complementarios de tipo biológico y tanatoquímico, incidiendo de manera particular sobre el estudio de los componentes químicos (estroncio) y sobre el papel diagnóstico que puede representar el estudio de las diatomeas, con sus posibles causas de error. También se analizan las aportaciones diagnósticas que pueden realizar, en determinados casos, el estudio de los protozoos ciliados, las algas verdes o el análisis bacteriológico de la sangre. Otros marcadores son objeto de consideración, y de manera particular, el estudio del surfactante pulmonar que está abriendo nuevas vías de diagnóstico en los cuadros de sumersión. Se formulan, finalmente, algunas consideraciones en torno a los diferentes procedimientos propuestos para el establecimiento de la data de la muerte.

Palabras clave: Patología forense. Sumersión. Revisión.
\end{abstract}

Cuad Med Forense 2007; 13(48-49):99-130

Ponencia presentada en el III Mediterranean Academy of Forensic Sciences Congress,

V Latin-American Congress of Medical Law, III Iberian Congress of Legal Medicine.

Oporto (Portugal), 21-23 de junio de 2007.

\section{ABSTRACT}

The recovery of a corpse from the water raises always multiple and varied questions, to which it is not possible to find an adequate answer in some occasions, in spite of the richness of signs that use to offer the cases of asphyxia by drowning.

In this paper, a critical review and update of deaths by drowning is presented, taking into account the recent knowledge on the physiopathological alterations induced by these pictures, with special interest to the cases of bodies recovered of the water with "dry lungs ". The postmortem findings are reviewed, as well as the histopathological and histoenzymatic studies. A wide review of the ancillary examinations from biology to tanatochemistry is also performed, stressing particularly the study of the chemical components (Strontium) and the diagnostic role that can represent the study of diatoms, with their possible causes of error. The diagnostic contributions that can made, in certain cases, the study of the ciliated protozoa, the green algae or the bacteriological analysis of blood are also analyzed. Other markers are object of consideration, specifically the study of the pulmonary surfactant that is opening new diagnostic ways in drowning cases. Finally, some considerations concerning the different procedures proposed for the establishment of the time of death are formulated.

Key words: Forensic pathology. Drowning. Review.

\footnotetext{
Correspondencia: José-Luis Romero Palanco. Departamento de Medicina Legal y Forense. Facultad de Medicina. Plaza Fragela s/n. 11003 Cádiz. Tfno: 956015190.

1 Catedrático de Medicina Legal y Forense. Universidad de Cádiz.
} 


\section{INTRODUCCIÓN:}

La recuperación de un cadáver del agua plantea siempre múltiples y variadas preguntas a las que es necesario dar cumplida respuesta, a fin de resolver los diferentes problemas que se plantean, desde el punto de vista médico forense:

- ¿Quién es la víctima?

- ¿Estaba viva la víctima antes de entrar en el agua?

- iFalleció por una causa natural o violenta antes del ingreso en el agua?

- ¿Le sobrevino una muerte natural o violenta en el agua?

- ¿Sufrió una muerte por inhibición en el agua?

- ¿Sufrió un cuadro de hipotermia en el agua?

- ¿Precipitó la hipotermia el fallecimiento en el agua?

- ¿Sufrió un cuadro de asfixia por sumersión?

- ¿Por qué motivo fue incapaz de sobrevivir en el agua?

- ¿Pudo influir en el fatal desenlace algún tóxico?

- ¿Cuánto tiempo ha permanecido en el agua?

Éstas y otras múltiples cuestiones derivadas de cada una de ellas, hacen que la investigación en los casos de cuerpos recuperados del agua sea sumamente compleja y difícil. Puede afirmarse que es necesario correlacionar todos los hallazgos necrópsicos, que en estos supuestos son muy abundantes, con los resultados de las pruebas analíticas complementarias, así como con los datos facilitados por la investigación policial, que, aun siendo siempre necesaria, en estos casos requiere una más intensa colaboración [I].

\section{CONCEPTO:}

Una de las definiciones clásicas de la muerte por sumersión es la debida a Roll [2], quien la definía como el resultado de obstaculizar la respiración por obstrucción de la boca y la nariz por un medio fluido, generalmente agua. Son muchas las definiciones que en la literatura podemos encontrar sobre este cuadro, si bien algunas de ellas pueden resultar incorrectas o incompletas a la luz de los conocimientos actuales.

Modell [3] la definía en 198I ("drowning"), como sofocación por sumersión, especialmente en agua, distinguiéndolo de "near-drowning", que define como supervivencia, al menos temporal, tras la sofocación por sumersión en agua. Otros autores precisan la duración de este período en al menos 24 horas tras la sumersión, con independencia del resultado final [4-6]. Recientemente y de forma más precisa, el Primer Congreso Mundial sobre asfixia por sumersión, celebrado en Amsterdam (Holanda) en el año 2002, ha venido a definirla como el proceso de experimentar insuficiencia respiratoria por la sumersión o inmersión en un líquido ("Drowning is the process of experiencing respiratory impairment from submersion/immersion in liquid") [7-9]. En dicho Congreso ha existido un cierto consenso para que el término "near-drowning" sea abandonado como tal, ya que resulta confuso e impreciso en la literatura médica de carácter clínico. Con ello se pretende dar fin al extraordinario número de definiciones y cuadros patológicos que se han venido dando sobre esta particular cuestión. Papa et al [10], en una revisión efectuada entre los años 1966 y 2002, han encontrado 20 definiciones diferentes para sumersión, 13 definiciones diferentes para "near-drowning" y 13 términos relacionados en un total de 43 artículos revisados.

Concheiro y Suárez [I I], definen la sumersión, en sentido médico-legal, como la muerte o el trastorno patológico producidos por la introducción de un medio líquido, habitualmente agua, en las vías respiratorias. Distinguen entre sumersión primaria, cuando la muerte sigue inmediata- 
mente a la sumersión, y sumersión secundaria, cuando la penetración líquida ocasiona tan sólo un trastorno patológico que, eventualmente, puede ocasionar también la muerte en un momento posterior. Coincidimos plenamente con estos autores en la conveniencia de no incluir bajo el concepto de sumersión los cuadros resultantes de la penetración de material semilíquido o pastoso en las vías aéreas, ya que los trastornos fisiopatológicos resultantes no vienen a coincidir con los producidos por el agua y son mucho más parecidos a los que se producen en los casos de sofocación por obstrucción intrínseca de las vías respiratorias.

\section{DATOS EPIDEMIOLÓGICOS:}

Aproximadamente medio millón de personas mueren cada año en todo el mundo a causa de una asfixia por sumersión [10, 12] y se estima que dicha cifra está muy por debajo de las cifras reales, ya que muchos casos no son informados o registrados [13].

Datos disponibles de la OMS vienen a poner de manifiesto unas tasas de mortalidad de 6.8 por 100.000 habitantes [14]. Estas cifras colocan a la asfixia por sumersión como la segunda causa de muerte no intencional, tras las producidas por accidentes de tráfico [9].

En un gran número de países desarrollados, la asfixia por sumersión tiene una alta incidencia en niños menores de 5 años y en jóvenes con edades comprendidas entre 14 y 24 años [15-19], constituyendo la primera o segunda causa de muerte en estos grupos de edad.

En la Tabla I se muestran las tasas de mortalidad para esta variedad de asfixia.

\begin{tabular}{|c|c|c|c|c|c|c|c|}
\hline \multicolumn{6}{|c|}{ Tabla I: MUERTES POR SUMERSIÓN Y SEXOS Y REGIÓN WHO (GBD 2000) } \\
\hline & $\begin{array}{c}\text { World } \\
\text { Total }\end{array}$ & AFR & AMR & EMR & EUR & SEAR & WPR \\
\hline Males & 281.717 & 67.654 & 20.181 & 20.712 & 30.322 & 55.258 & 87.600 \\
\hline Females & 127.555 & 23.311 & 4.408 & 6.904 & 7.196 & 36.520 & 49.216 \\
\hline Total & 409.272 & 90.965 & 24.589 & 27.616 & 37.518 & 91.778 & 136.816 \\
\hline Sex ratio & $2.2: 1$ & $2.9: 1$ & $4.6: 1$ & $3: 1$ & $4.2: 1$ & $1.5: 1$ & $1.8: 1$ \\
\hline$\%$ & 100 & 22.3 & 6 & 6.8 & 9.1 & 22.4 & 33.4 \\
\hline $\begin{array}{c}\text { Rate por } \\
100.000\end{array}$ & 6.8 & 14.2 & 3 & 5.7 & 4.3 & 6 & 8.1 \\
\hline $\begin{array}{l}\text { AFR = African Region; AMR = American Region; EMR = Eastern Mediterranean Region; EUR = European Region; } \\
\text { SEAR = South-East Asian Region; WPR = Western Pacific Region. }\end{array}$ \\
\hline
\end{tabular}

\section{ETIOLOGÍA MÉDICO-LEGAL:}

La asfixia por sumersión, como mecanismo de muerte, reconoce en la inmensa mayoría de los casos una etiología accidental, que tiene una especial incidencia en menores de 5 años y en jóvenes con edades comprendidas entre 15 y 24 años, predominando estos tipos de muerte en sujetos varones y en los meses de verano. Con gran frecuencia va asociada con el consumo de alcohol u otros tóxicos [20-22].

La asfixia por sumersión de etiología suicida tiene una incidencia significativamente menor que la etiología accidental. (Tabla II). Asimismo, al estudiar el total de los procedimientos suicidas, la asfixia por sumersión no constituye un procedimiento de elección en nuestro medio (Tabla III), siendo 
ampliamente sobrepasada por la precipitación, la ahorcadura, el empleo de tóxicos y, en algunos países, por el uso de armas de fuego. En los casos de etiología suicida existe una mayor incidencia de mujeres y de grupos de edad mayores que en los casos de etiología accidental. En algunas publicaciones se ha señalado la inmediatez de la costa, ríos o lagos para justificar el empleo de este procedimiento, extremo éste que no coincide con los datos que hemos obtenido en Huelva y en Cádiz [23-24], pese a concurrir aquella circunstancia. Desde otro punto de vista, en la revisión que llevamos a cabo sobre el suicidio consumado en la ciudad de Sevilla [25-26] pudimos comprobar que la frecuencia de la asfixia por sumersión como procedimiento suicida ha ido decreciendo en los últimos años. La etiología suicida también se asocia con gran frecuencia con el consumo de alcohol o drogas tóxicas [27-30].

Por lo que hace referencia a la etiología homicida de la sumersión, ésta es muy poco frecuente (Tabla II), requiriendo una gran desproporción de fuerzas entre el agresor y la víctima o bien que esta última se encuentre indefensa por traumatismos previos o por la administración de alcohol y/o tóxicos. Tras una revisión de 2.617 homicidios, Copeland [3।], encontró un total de 12 casos, lo que representa una incidencia del $0.46 \%$. En otro estudio [32], que abarcaba desde 1956 a 1982 , encontró que en el $34 \%$ de los homicidios las víctimas eran menores de 12 años, habiendo fallecido por asfixia mecánica ( $18.7 \%$ ) o por sumersión (I 5.3\%). La revisión llevada a acabo por Rogde et al [33] en 94 homicidios cometidos en Oslo y Copenhague mediante procedimientos asfícticos, viene a poner en evidencia también la baja incidencia de la asfixia por sumersión, así como la gran proporción de mujeres y niños entre las víctimas.

Establecer la etiología médico-legal de la asfixia por sumersión ofrece una gran dificultad en la práctica, excediendo en muchos casos las posibilidades con las que cuenta el patólogo forense; es totalmente necesaria, como ya se ha indicado, una colaboración más estrecha con los agentes policiales, a efectos de dar una adecuada respuesta a esta particular cuestión.

\begin{tabular}{|l|c|c|c|c|c|}
\hline \multicolumn{7}{|l|}{ Tabla II: ETIOLOGÍA DE LAS MUERTES POR SUMERSIÓN } \\
\hline Autor & № casos & Accidentes & Suicidios & Homicidios & Indeterm. \\
\hline Press et al [34] & 1.201 & $84.6 \%$ & $3.6 \%$ & $0.33 \%$ & $11.32 \%$ \\
\hline Wirthwein et al [35] & 1.303 & $90.5 \%$ & $4 \%$ & $2.5 \%$ & $3 \%$ \\
\hline Wintemute et al [36] & 137 & $95 \%$ & & $1 \%$ & $4 \%$ \\
\hline Gamero et al [37] & 314 & $57 \%$ & $42.67 \%$ & $0.33 \%$ & \\
\hline Gorniak et al [20] & 187 & $78 \%$ & $14 \%$ & $3 \%$ & $6 \%$ \\
\hline Lucas et al [38] & 123 & $13 \%$ & $42.2 \%$ & $4.06 \%$ & $40.6 \%$ \\
\hline Davis [29] & 267 & & $9.36 \%$ & & \\
\hline
\end{tabular}




\begin{tabular}{|l|c|c|}
\hline Tabla III: LA SUMERSIÓN COMO PROCEDIMIENTO SUICIDA \\
\hline Autor & № suicidios & $\begin{array}{c}\text { Asfixia por } \\
\text { sumersión }\end{array}$ \\
\hline Wirthwein et al [35] & 6.082 & 0.85 \\
\hline Byard et al [27] & & 3.6 \\
\hline Avis [28] & 247 & 8.9 \\
\hline Copeland [30] & & 4.5 \\
\hline Davis [29] & & 2.86 \\
\hline Romero [25] (Sevilla, 1953-1977) & 800 & 18.87 \\
\hline Romero et al [26] (Sevilla, 1978-1987) & 505 & 10.13 \\
\hline Romero et al [24] (Cádiz, 1999-2003) & 263 & 3.04 \\
\hline Auer [39] & & 7.9 \\
\hline
\end{tabular}

\section{FISIOPATOLOGÍA Y MECANISMOS DE MUERTE:}

Las primeras referencias de carácter experimental en animales (perros) sobre la sumersión se deben a Brouardel y Vibert [40] y Brouardel y Loye [4I], llevadas a cabo en I880 y I889, respectivamente. A partir de sus observaciones, describieron cinco fases en los casos de asfixia por sumersión:

$I^{a}$ fase: En el momento mismo de la inmersión, el animal realiza una o varias inspiraciones forzadas, durando esta fase 5 o 6 segundos.

$2^{\text {a }}$ fase: El animal de experimentación se agita violentamente; trata de salir con la boca cerrada. La respiración está detenida. La duración de esta fase es de un minuto aproximadamente.

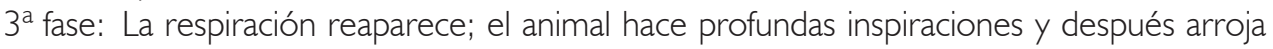
espuma blanca. Casi al mismo tiempo los movimientos generales del cuerpo cesan. El perro permanece de costado, con la boca y los ojos abiertos y realiza movimientos de deglución. Esta fase dura también un minuto.

$4^{a}$ fase: Nueva parada de la respiración; el tórax permanece inmóvil, desapareciendo la sensibilidad; midriasis. Dura esta fase un minuto.

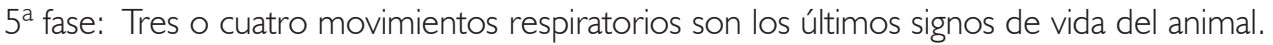
Estos movimientos persisten aproximadamente durante medio minuto. Al mismo tiempo aparecen contracciones en el hocico y en la mandíbula.

Pese a que estas experiencias con animales se han llevado a cabo por muy diferentes autores, a los que nos referiremos más adelante, los mecanismos exactos de la asfixia por sumersión en humanos siguen siendo desconocidos en muchos aspectos [42]. Buena prueba de cuanto afirmamos son las diferentes clases o tipos de sumersión que, bajo esta común e inespecífica denominación, podemos encontrar en la bibliografía especializada.

A efectos de nuestra exposición y atendiendo estrictamente a los mecanismos fisiopatológicos por los que se producen estos tipos de muerte, distinguiremos entre asfixia por sumersión y muertes en el agua con pulmones secos. 


\section{ASFIXIA POR SUMERSIÓN:}

Las circunstancias previas en las que acontece este tipo de muerte pueden ser muy variadas [43]. En unos casos el sujeto deja de nadar súbitamente y se sumerge, en otros se queda inmóvil encontrándose bajo la superficie del agua, en otros sale y se sumerge de forma rápida y consecutiva en el agua, lo que puede explicar los variados hallazgos necrópsicos y los diferentes mecanismos por los que la muerte se produce.

Habitualmente, en los casos de etiología accidental se produce una fase inicial de lucha desordenada con movimientos de los brazos y piernas intentando mantenerse a flote. En otros casos, tratándose de personas que saben nadar, pero que por las circunstancias que fueren quedan inmovilizadas bajo el agua, van a dejar de respirar de forma voluntaria, produciéndose una situación de hipoxia. Al mismo tiempo, de forma instintiva o refleja, el sujeto va a tragar una mayor o menor cantidad de agua, que es capaz, en algunos casos, de provocar el vómito [44]. Finalmente, la severa hipoxia llevaría a una situación de inconsciencia, pérdida de reflejos de las vías respiratorias y posterior entrada de agua en los pulmones [45].

Sin perjuicio de lo anterior, otros autores señalan que tras la inspiración profunda que realizarían los individuos antes de hundirse bajo el agua, se asistiría a una situación de apnea voluntaria que se mantendría hasta que las bajas concentraciones de oxígeno y la hipercapnia les obligasen a una inspiración forzada, por estimulación de los centros respiratorios a través de los quimiorreceptores de los senos carotídeos [ I I , 46], la cual conduciría a una inhalación masiva de líquido [47]. La penetración del líquido llevaría a una situación de disnea o polipnea, con movimientos respiratorios incoordinados, así como a la aparición de un cuadro convulsivo [I I , 48]. La respiración cesa finalmente y se instaura una anoxia cerebral irreversible.

Zangani et al [49] sistematizan lo anterior en las siguientes fases:

- I a fase o de sorpresa, en que se realiza una profunda inspiración fuera del agua.

- $2^{a}$ fase o de apnea, para evitar la penetración del agua.

- $3^{a}$ fase o de disnea, en que se realiza la inhalación de agua, que va seguida de una disnea espiratoria por estimulación del agua sobre la mucosa laríngea.

- $4^{a}$ fase o de convulsiones asfícticas, en la que el líquido continúa penetrando de forma discontinua en las vías respiratorias.

- $5^{a}$ fase o fase terminal que se comprueba con la realización de una o más inspiraciones profundas, que van precedidas de una pausa respiratoria preterminal.

La penetración de la columna líquida en las vías respiratorias, llegando a inundar los alvéolos pulmonares, conlleva unos efectos mecánicos de carácter inmediato: De una parte, se va a mezclar el aire residual pulmonar con el agua y con sustancias y secreciones pulmonares, dando lugar a la formación de una materia espumosa que ocupará las vías respiratorias, pudiendo exteriorizarse a través de la boca y de los orificios nasales, dando lugar al denominado "hongo de espuma".

De otra parte, la presión ejercida por la columna líquida sobre el propio aire residual existente en los pulmones, provocará lesiones en el tejido pulmonar, que constituyen parte de los hallazgos anatomopatológicos, tales como zonas de dilatación alveolar, adelgazamiento y rotura de las paredes alveolares, rotura de capilares perialveolares, así como el denominado enfisema hidroaéreo.

Estas lesiones pulmonares agudas y el síndrome de insuficiencia respiratoria severa pueden apreciarse incluso con pequeñas cantidades de líquido inspirado [50, 51$]$. 
Se pensó que la anoxia anóxica era el mecanismo por el que se explicaba la muerte por sumersión, pero a partir de los trabajos de Swann et al $[52,53]$ y de otros investigadores [54], se concedió una gran importancia a las alteraciones electrolíticas que el agua podía producir al ingresar en el torrente circulatorio, estimándose que las concentraciones de electrolitos en suero podrían ser muy variadas, dependiendo de la cantidad y el tipo de líquido aspirado [55]. No obstante, en casos de sumersión con supervivencia se ha podido comprobar que las alteraciones electrolíticas no fueron altamente significativas y usualmente eran compatibles con la vida [56, 57].

Dichas alteraciones van a estar condicionadas por la osmolaridad del líquido inspirado. En los casos de sumersión en agua dulce, la cual es hipotónica con respecto al plasma, cuando llega a los alvéolos es rápidamente absorbida, pasando a la circulación pulmonar. Ello provoca una marcada hemodilución y una hipervolemia, que en algunos casos puede significar un incremento del 30 al 50\% [58]. Esta dilución extrema podría producir una situación de hiponatremia, con sobrecarga circulatoria, facilitando la aparición de insuficiencia cardíaca.

Asimismo, se va a producir hemólisis por la entrada del líquido de sumersión en el torrente circulatorio, lo que provoca una hiperkaliemia y las consiguientes arritmias, que pueden llevar a la muerte del sujeto en muy pocos minutos. De otra parte, la aspiración del agua dulce afecta de manera fundamental a los fosfolípidos del surfactante pulmonar [59], lo que hace inestables a los alvéolos, favoreciendo la aparición de zonas de atelectasia [60]. Igualmente, los líquidos isotónicos pueden ejercer un efecto citotóxico directo sobre las células endoteliales alveolares y vasculares, provocando una hinchazón de las mismas, que puede conducir a la rotura de las membranas celulares, favoreciendo así la formación de edema intersticial y alveolar.

En los casos de sumersión en agua salada, la cual es hipertónica respecto al plasma, ocurre todo de forma distinta. El líquido de sumersión que ocupa la luz intraalveolar, que puede sobrepasar en tres o cuatro veces la osmolaridad de la sangre [6 l], atrae agua a las vías respiratorias desde la circulación pulmonar, causando, consiguientemente, hipovolemia, hemoconcentración y edema pulmonar grave. Se produce un incremento de la viscosidad de la sangre e hipernatremia aguda; por su parte, el edema pulmonar incrementa aún más la situación de hipoxia e hipercapnia, llevando por último al corazón a una situación de bradicardia y asistolia [58]. Se han citado casos de sumersión con supervivencia en agua salada, en los que el cuadro clínico de la inhalación se vio intensamente agravado por la deglución de una cantidad importante de agua salada, lo que condujo rápidamente a una situación clínica de hipernatremia grave [62]. El cuadro aún podría agravarse más si el líquido de sumersión está muy contaminado por materias o cuerpos en suspensión, los cuales podrían obstruir bronquios y bronquiolos [63].

No obstante lo anterior, trabajos experimentales en perros llevados a cabo por Orlowski et al [42], permitieron a éstos concluir que los efectos cardiovasculares apreciados en la asfixia por sumersión no dependían totalmente de la osmolaridad del líquido aspirado, sino que eran el resultado directo de la anoxia. A conclusiones similares habían llegado Modell [64] y Pearn [65], unos pocos años antes.

Pese a que inicialmente se había pensado que la parada cardiovascular en los ahogados se debía a las graves alteraciones electrolíticas, asociadas a grandes volúmenes de líquido inspirado, desde fechas recientes se estima que la cantidad de líquido en sujetos adultos rara vez sobrepasa la cantidad de $7 \mathrm{~mL} / \mathrm{Kg}$ de peso [5l]. Por tanto, las alteraciones del ritmo cardíaco y, finalmente, la parada cardíaca, derivan de forma fundamental de la prolongada hipoxia, las alteraciones severas del equilibrio ácido-base, la descarga de catecolaminas y, a veces, la influencia de la hipotermia por la baja temperatura del agua [45]. 
Hoy se piensa que la mayor parte de los efectos cardiovasculares de la asfixia por sumersión son fundamentalmente secundarios a la hipoxia [66]. La hipoxemia inicial sufrida por las víctimas de asfixia por sumersión se debe a la apnea, pero después se relaciona más con la lesión pulmonar aguda que se desarrolla como resultado de las alteraciones del surfactante pulmonar, con colapso alveolar y atelectasia [67]. De otra parte, la grave disfunción pulmonar sufrida por muchas víctimas de sumersión conduce a una insuficiencia respiratoria e hipoxia, que pueden ser suficientes para provocar una parada cardíaca $[43,68]$.

Se ha comprobado experimentalmente en animales que la hipoxia severa, junto con la situación de estrés sufrida durante los primeros momentos de la sumersión, facilitarían la liberación masiva de catecolaminas, provocando así una vasoconstricción generalizada [69]. Los niveles altos de catecolaminas, unidos a la hipoxia y a la acidosis, podrían provocar un fallo cardíaco, el cual podría acompañarse, además, de la liberación de mediadores inflamatorios por parte de las células endoteliales, bajo el estímulo de la situación de hipoxia.

\section{MUERTES EN EL AGUA CON PULMONES SECOS:}

Se ha citado clásicamente que entre un 10-15\% de los cuerpos recuperados del agua no tenían líquido en los pulmones, lo que ha motivado alguna polémica en torno a si es adecuado o no hablar de "sumersión sin aspiración" (drowning without aspiration) [70]. Se ha sugerido por muy diferentes autores que un espasmo de glotis podría ser el mecanismo que impidiese la entrada del agua en las vías respiratorias [44, 6I, 70, 71,72]. La apnea inicial podría estimular los quimiorreceptores carotídeos, contribuyendo al desencadenamiento de una parada cardíaca de origen vagal [73], la cual podría ser igualmente facilitada al entrar en contacto con el agua.

En la revisión que llevan a cabo Lunetta y Modell [74], éstos afirman que el volumen de líquido aspirado varía considerablemente de unas víctimas a otras y que depende de factores tales como la frecuencia y duración del laringoespasmo, el número y profundidad de los movimientos respiratorios realizados antes de la muerte, y el tiempo transcurrido hasta la parada cardíaca. Para dichos autores, los pulmones secos pueden tener varias explicaciones además del laringoespasmo, citando entre ellos la inhibición cardíaca vagal desencadenada por el contacto del agua con las vías respiratorias superiores, la parada cardíaca súbita o algunos reflejos pulmonares [50].

El concepto de "dry-drowning" ha sido reconsiderado recientemente y se ha sugerido que su incidencia real es más baja que la que se había estimado con anterioridad, alcanzando tan sólo al $2 \%$ [75]. Asimismo, estiman que los cuerpos humanos encontrados en el agua con pulmones aparentemente normales podrían encubrir más casos de muertes naturales en el agua de los que son habitualmente reconocidos.

La hipótesis del laringoespasmo tiene su fundamento en la inervación compleja y en los reflejos de las vías aéreas superiores bajo diversos estímulos. Sin embargo, no existen pruebas en humanos que pongan en evidencia la existencia de dicho laringoespasmo prolongado o persistente hasta el momento de producirse la muerte, a fin de impedir la entrada de agua en las vías respiratorias. Por el contrario, en trabajos de carácter experimental en animales se ha podido comprobar que el laringoespasmo cesa en los dos minutos que siguen al comienzo de la sumersión [76, 77].

No parece quedar duda alguna de que las muertes denominadas por inhibición vagal o hidrocución, podrían formar parte del grupo que acabamos de considerar. Se trata de un grupo de muertes que suceden súbitamente en el agua, cuyo mecanismo es atribuido a una inhibición cardiaca refleja por estimulación de las terminaciones del vago y que conducirían, asimismo, a un cuadro de "sumersión sin aspiración". 
Conocidos estos tipos de muerte a través de las observaciones realizadas por Spilsbury [78], su mecanismo es aceptado tras la revisión efectuada por Simpson [79]. No se trata, por consiguiente, de una asfixia por sumersión propiamente dicha, habida cuenta que el agua no va a penetrar en las vías respiratorias. El cuadro necrópsico, aunque inespecífico, podría remitirnos a su verdadero origen, al descartarse el mecanismo asfíctico.

El reflejo inhibitorio podría tener como punto de partida, como ya se ha señalado, la mucosa nasal, nasofaríngea o laríngea al contactar el agua de forma repentina con ellas. En este sentido, se ha postulado que una gran diferencia de temperatura entre el líquido de sumersión y la temperatura corporal podría contribuir o desencadenar por sí misma este cuadro, al tomar contacto el agua con la superficie corporal de la víctima. En otros casos, la zona reflexógena a partir de la cual se desencadenaría el reflejo inhibitorio podría radicar en el plexo solar, en caídas de altura sobre la región gástrica e incluso a nivel del escroto. La aparición de estos tipos de muerte puede verse favorecida cuando la víctima se encuentra bajo la influencia del alcohol u otras sustancias tóxicas y, en todo caso, cuando la temperatura del agua es muy baja [80].

Indican algunos autores que la hipotermia suele estar asociada a los cuadros de asfixia por sumersión, sobre todo en el caso de los niños [12]. Cuando la temperatura corporal disminuye, el temblor aumenta el consumo de oxígeno y la actividad metabólica, en un intento de aumentar la producción de calor. Por debajo de $30^{\circ} \mathrm{C}$, el temblor cesa, el ritmo cardíaco se enlentece, disminuye la presión sanguínea, y el consumo de oxígeno y la velocidad metabólica también disminuyen. Los pacientes se encuentran de este modo en una situación de riesgo de bradicardia extrema, asistolia o fibrilación ventricular [8I]. De forma paradójica, la sumersión en agua fría se asocia, en los casos de supervivencia, con un mejor pronóstico que en agua caliente, sobre todo en niños [82].

El choque térmico producido por la diferencia de temperatura entre el agua y el cuerpo de la víctima también podría facilitar el desencadenamiento de crisis de fibrilación ventricular [83]. Ackerman et al $[84,85]$ formularon la hipótesis de que algunos casos de muerte en el agua, sobrevenida en excelentes nadadores, podrían tener una base genética, relacionada con el síndrome del QT largo. Esta circunstancia ha sido igualmente señalada por Lunetta et al [86], quienes, tras la revisión efectuada en 165 cadáveres encontrados en el agua, comprobaron una mutación del gen LQT2 (responsable de la fase 2 de la repolarización), en una mujer de 44 años, cuya muerte fue inicialmente establecida de etiología suicida; estos autores resaltan el valor del análisis genético del síndrome del QT largo en casos de sumersión, a efectos de aclarar algunos fallecimientos sin causa aparente en nadadores expertos y sobrios. A conclusiones similares llegan Choi et al [87], tras estudiar 388 pacientes a través del test genético para el síndrome del QT largo.

No cabe duda alguna que la investigación molecular debe incorporarse a la práctica médico-forense para esclarecer muchas causas de muerte que, aún hoy, permanecen ocultas, y de manera particular, a los casos de cuerpos recuperados del agua cuyos hallazgos necrópsicos no coincidan con el cuadro de la asfixia por sumersión.

\section{HALLAZGOS NECRÓPSICOS:}

El capítulo de la asfixia por sumersión suele ser ampliamente tratado en todos los libros de texto de Medicina Legal [I I , 46, 47, 48, 49, 88-93], mereciendo destacar las revisiones llevadas a cabo recientemente por Lunetta y Modell [74] y por Shkrum y Ramsay [73], así como la publicada por Piette y De Letter [94]. 


\section{EXAMEN EXTERNO:}

I. I. Hongo de espuma. La identificación del hongo de espuma sobre los orificios nasales y la boca constituye un elemento indicativo de asfixia por sumersión. Típicamente aparece de color blanquecino o sonrosado, constituido por burbujas homogéneas de pequeño calibre. Su presencia no es constante, habiéndose identificado en el $17.3 \%$ de 1.590 casos revisados por Lunetta et al [95]. En unos casos, cuando la observación del cadáver se hace de forma inmediata al fallecimiento, es posible que no haya aflorado todavía al exterior, mientras que en otros, si la recuperación del cadáver se hace de forma tardía, es posible que se haya producido el limpiamiento o arrastre del mismo por la acción del agua. En todo caso, es un signo que viene a poner de manifiesto la existencia de un cuadro de edema pulmonar, motivo éste por el cual suele observarse también en otros casos de muertes que cursan con un fracaso agudo del ventrículo izquierdo [47].

I.2. Espasmo cadavérico. En algunas ocasiones puede apreciarse un espasmo localizado a nivel de las manos, cuyos dedos, fuertemente flexionados, suelen retener arena o briznas de vegetación o algas del fondo del río, lago o mar donde se produjo la sumersión. Tiene un claro significado de reacción vital [I I, 58], que pone de manifiesto los últimos momentos de la vida del ahogado ("Agarrarse a un clavo ardiendo", "A drowning man will catch at straws").

I.3. Livideces cadavéricas. También tendría esta significación vital la coloración más clara de lo habitual de las livideces cadavéricas, la cual podría atribuirse a la dilución que experimenta la sangre, tras penetrar el líquido de sumersión en el torrente circulatorio. No obstante, dicha coloración podría estar influida también por la baja temperatura del medio de sumersión. Además, debe tenerse presente que, cuando el cadáver se encuentra en un medio con fuertes corrientes o amplias variaciones de mareas, su continua movilidad, sin tener un plano declive claramente definido, puede condicionar que las livideces sean prácticamente imperceptibles. En otros casos, dado que durante la permanencia del cadáver en el agua, éste suele adoptar una posición próxima al decúbito prono, no será extraño identificar las livideces en el plano anterior del tronco [48].

I.4. Como consecuencia de la permanencia prolongada del cadáver en el agua, éstos, cualquiera que haya sido la causa de la muerte, pueden presentar los signos siguientes:

- Piel con aspecto anserino (cutis anserina), consecuencia del proceso de rigidez que sufren los músculos erectores del pelo, la cual se ve favorecida, en su caso, por la baja temperatura del medio de sumersión.

- Se asiste también a un enfriamiento corporal precoz, tanto más rápido cuanto más baja sea la temperatura del medio de sumersión. El íntimo contacto entre el agua y la superficie corporal provoca una rápida nivelación de la temperatura, no interferida por la presencia de los vestidos.

- Entre los fenómenos más llamativos y frecuentes en los cuerpos recuperados del agua están las manifestaciones debidas al proceso de maceración cutánea o imbibición acuosa que sufre la capa córnea de la piel, más evidentes a nivel de las palmas de las manos y plantas de los pies, dando lugar a las denominadas "manos de lavandera" ("washerwoman's hands"). En los momentos iniciales aparece como blanqueamiento, engrosamiento y arrugamiento de la epidermis, pero cuando la permanencia en el agua se prolonga, acaba desprendiéndose en forma de guante o calcetín; también los pelos y las uñas pueden desprenderse con facilidad. Hemos tenido 
ocasión de apreciar este fenómeno en cadáveres de dieciocho personas de raza negra, cuya embarcación se hundió accidentalmente, los cuales, tras una permanencia en el agua de seis días aproximadamente, terminaron perdiendo la epidermis de forma generalizada, lo que en algunos casos extremos motivó dudas acerca de la raza a la que pertenecían. La imbibición acuosa del cuero cabelludo era tan intensa que sufría una fácil deformación por su propio peso, llegando en algunos casos a presentar soluciones de continuidad e incluso la pérdida total del mismo, con una evidente esqueletización de la cabeza.

- Por lo que se refiere a la evolución de la putrefacción cadavérica, es bien conocido que está influenciada por la temperatura del medio en que el cadáver está sumergido. El desarrollo de los gases durante la fase enfisematosa es el responsable de que los cadáveres sumergidos vuelvan a la superficie. Asimismo, en términos generales, puede decirse que en tanto el cadáver permanece sumergido, la putrefacción parece seguir un ritmo más lento que si se encontrase al aire libre. Una vez recuperado el cadáver del agua, la putrefacción se acelera considerablemente.

- Cuando la permanencia prolongada del cadáver tiene lugar en agua estancada o con poca corriente, se aprecia una tendencia a sufrir el proceso de saponificación, tanto más acusada cuanto más factores predisponentes concurran en cada caso, siendo de especial interés la abundancia de tejido graso en el cadáver.

- Además de los signos anteriores, no es infrecuente encontrar lesiones externas, de diferente naturaleza, en los cadáveres recuperados del agua, las cuales pueden dar lugar a problemas de interpretación [96]. En algunos casos, las lesiones tienen un marcado carácter vital, obedeciendo a otras tentativas suicidas previas a la sumersión, o a lesiones de etiología homicida, tendentes a aturdir a la víctima mediante golpes, casi siempre a nivel de la cabeza; en otros casos, las lesiones obedecen a un mecanismo contusivo grave al caer sobre un fondo rocoso o sólido. En la mayoría de los casos, o bien coexistiendo con algunas de las lesiones anteriores, pueden encontrarse lesiones postmortem que se producen por el arrastre del cadáver sobre las irregularidades del fondo, bajo la acción de las corrientes de agua, dando lugar a erosiones, excoriaciones o heridas contusas, que suelen radicar en la región frontal, dorso de las manos, rodillas y dorso de los pies, dada la especial posición que adoptan los cadáveres sumergidos.

En algunos casos se producen lesiones artefactuales al intentar recuperar los cadáveres del agua (bicheros), e incluso otros presentan lesiones producidas por las palas de las hélices de las embarcaciones. Es también posible observar lesiones en las partes blandas de la cara, manos y pies, producidas por peces, crustáceos y otros animales marinos.

\section{EXAMEN INTERNO:}

Los hallazgos necrópsicos más característicos de la asfixia por sumersión van a asentar en el aparato respiratorio y están directamente relacionados con la penetración del líquido de sumersión en las vías respiratorias.

2.1. Hemorragias intramusculares. Se han descrito hemorragias localizadas a nivel del cuello, tronco y extremidades superiores [97, 98], cuyo mecanismo se ha atribuido a las convulsiones agónicas y al sobreesfuerzo realizado por los diferentes grupos musculares durante la anoxia. Se trata de un hallazgo controvertido, ya que otros investigadores del tema [99], tras la revisión de 
2.060 autopsias, concluyeron que las hemorragias localizadas en los músculos cricoaritenoideos no guardan relación alguna con la causa o mecanismo de la muerte.

2.2. Los pulmones ofrecen el cuadro más rico y característico de la asfixia por sumersión. Ambos pulmones aparecen extraordinariamente aumentados de volumen, hasta el punto de que llegan a solaparse los bordes anteriores de las lengüetas pulmonares, ocultando el saco pericárdico. Lunetta, Penttilä y Sajantila [95] encontraron este signo en el $42.1 \%$ de una serie de 1.590 casos. Como consecuencia de este aumento de volumen, al retirar el peto esterno-costal en la apertura de la cavidad torácica, los pulmones parecen querer salir de las cavidades pleurales, siendo un hallazgo frecuente las marcas dejadas por las costillas sobre las superficies pulmonares.

Diseminadas por la superficie pulmonar aparecen las equimosis o manchas de Paltauf, de localización subpleural, de coloración más clara y de mayor tamaño que las equimosis de Tardieu, las cuales están relacionadas con el proceso asfíctico, a la vez que con el componente traumático ejercido por la penetración del agua.

A la forcipresión se aprecia una crepitación característica debido a la existencia de enfisema y de edema, con una elasticidad manifiestamente disminuida, persistiendo la huella dejada por la presión (fovea).

Al corte crepitan, dejando escapar gran cantidad de aire, apreciándose una gran congestión pulmonar, fluyendo por las superficies de sección abundante sangre, de aspecto espumoso, mezclada con el líquido de sumersión. Asimismo, pueden apreciarse focos hemorrágicos intrapulmonares.

La tráquea y bronquios se encuentran ocupados por espuma blanquecina o sonrosada (mezcla de secreciones bronquiales, agua y aire, eventualmente teñida por sangre), que sido observada en el $46.5 \%$ de los casos [95], y que se continúa hacia el exterior dando lugar al hongo de espuma. En ocasiones, puede apreciarse también restos de productos del vómito y de la vegetación existente en el medio de sumersión.

Se ha estudiado el peso de los pulmones, pudiendo afirmarse, en términos generales, que en la asfixia por sumersión suele ser elevado respecto a otros tipos de muerte. De La Grandmaison et al [100], tras el estudio de 684 sujetos adultos fallecidos por traumatismos con un tiempo de supervivencia menor de una hora, determinaron que en el hombre el pulmón derecho pesa $663 \pm 239$ gramos y el izquierdo $583 \pm 216$ gramos; en la mujer, el derecho pesa $546 \pm 207$ gramos y el izquierdo $467 \pm 174$ gramos. En la Tabla IV se muestran los valores determinados por diferentes autores en casos de asfixia por sumersión.

\begin{tabular}{|c|c|}
\hline \multicolumn{2}{|c|}{ Tabla IV: PESO DE PULMONES EN LA ASFIXIA POR SUMERSIÓN } \\
\hline Copeland [101] & 1.400 gramos \\
\hline Kringsholm et al [21] & $1.411 \pm 396.4$ gramos \\
\hline Lunetta et al [95] & $1.391 \pm 401$ gramos \\
\hline
\end{tabular}

No se ha encontrado ninguna diferencia significativa entre el peso de los pulmones de ahogados en agua dulce o agua salada [2 I, I 0 l]. Para Hadley y Fowler [102], los pesos elevados son el resultado conjunto de la asfixia y de la aspiración del agua. Todo lo anterior les permite afirmar a Shkrum y Ramsay [73], que en adultos mayores de dieciocho años pesos superiores a mil gramos, 
serían significativos a efectos de distinguir entre casos de asfixia por sumersión y otras causas de muerte.

2.3. Cavidades pleurales. Con frecuencia aparecen ocupadas por líquido seroso o serohemático que, en fallecidos por causas diferentes a la sumersión, vienen a alcanzar los $40 \mathrm{~mL}$ en cada una de ellas [103]. Este signo carece de valor en los casos en los que la putrefacción está avanzada [46]. Se estima que, en los cuerpos recuperados del agua, dicho derrame pleural es la consecuencia de la difusión postmortem de los líquidos pulmonares [104]. Morild [105] encontró derrame en las cavidades pleurales en el 53.3\% de una muestra de 133 ahogados, mayores de 16 años, sin signos de putrefacción avanzada, con una media global de $432 \mathrm{~mL}$. Asimismo, comprobó que el derrame pleural aparecía con mayor frecuencia en los ahogados en agua salada (38\%) que en los ahogados en agua dulce (33\%), y que existía una relación evidente entre el intervalo postmortem y el volumen del derrame pleural, circunstancia ésta también señalada en otras investigaciones [21, 103, 106]. Yorulmaz et al [103] no encontraron diferencias significativas en los volúmenes del derrame pleural, al comparar los sujetos ahogados en agua dulce y en agua salada.

Asimismo, se ha estudiado la relación existente entre el volumen del derrame pleural y el peso de los pulmones, habiendo descrito algunos autores que existe una correlación entre la disminución del peso de los pulmones y el incremento que experimenta el volumen del derrame $[21,106]$; sin embargo, otras investigaciones no han confirmado este hallazgo [103, 105].

Más recientemente, Inoue et al [ 107$]$ han estudiado las concentraciones de sodio, potasio, cloro y proteínas totales en el derrame pleural, en animales de experimentación, y los resultados obtenidos permiten establecer diferencias entre los ahogados en agua dulce y en agua salada.

2.4. Corazón. Escasas son las referencias encontradas en la bibliografía consultada acerca del estado del corazón, indicándose que la dilatación del ventrículo derecho que puede apreciarse en algunos casos, es consecuencia de la situación de hipervolemia y de la resistencia vascular pulmonar [90]. Para otros autores [9/], se trata de un signo subjetivo e inespecífico, no merecedor de mayores consideraciones.

2.5. Aparato digestivo. En el transcurso de la autopsia puede comprobarse la presencia del medio de sumersión y cuerpos extraños que pudieran acompañarle, a nivel del estómago e incluso del intestino delgado, los cuales habrían sido deglutidos durante la primera fase de la sumersión [48]. Para otros autores, este hallazgo tendría un valor discutible, ya que el medio líquido podría penetrar postmortem, de forma pasiva y en pequeñas cantidades, si la presión hidrostática del agua es lo suficientemente alta, dependiendo además, entre otros factores, del tono muscular del esófago y del esfínter del cardias [9/], no guardando relación alguna con el proceso de la sumersión.

Reh [108] intentó reevaluar la presencia del líquido de sumersión en el aparato digestivo, encontrando que en 16 de 17 casos de cuerpos sumergidos, con un intervalo postmortem entre 15 minutos y 65 horas, no encontraron signos de penetración del líquido en el aparato digestivo.

Ciertamente se trata de un hallazgo que suele ofrecer amplias variaciones, en lo que se refiere al volumen de líquido contenido en el estómago, y coincidimos con otros autores, cuando afirman que, si la cantidad de líquido es superior a $500 \mathrm{~mL}$ en un sujeto adulto, se trata de una sumersión intravital, por cuanto que no es posible admitir una penetración postmortem tan abundante $[\mathrm{I} I \mathrm{l}]$. La presencia de agua en el duodeno, cuando la putrefacción aún no es evidente, tendría la misma significación. 
De forma ocasional pueden apreciarse desgarros de la mucosa gástrica, a la altura del cardias, consecuencia quizás de los vómitos producidos por la deglución de grandes cantidades de agua. Blanco et al [ 109] los han identificado en el 21 . I \% de los casos de sumersión, localizados con mayor frecuencia en el fundus (54.5\%).

2.6. Bazo. Reh [108] había observado, en los casos de sumersión, que el bazo aparecía pequeño y anémico en el $30 \%$ de los casos. Haffner et al [ I I 0], en un estudio retrospectivo llevado a cabo en 42 víctimas de asfixia por sumersión en agua dulce, encontraron pesos del bazo significativamente menores que los determinados en otras causas de muerte, alcanzando una diferencia de peso del orden del I8\%. Atribuyeron esta disminución a la estimulación simpática con vasoconstricción y contracción de la cápsula esplénica y de las trabéculas. Hadley y Fowler [102] estiman que la disminución de peso del bazo es un fenómeno postmortem en los casos de sumersión prolongada. Más recientemente, Nishitani et al [l l l l] encuentran diferencias significativas entre los sujetos fallecidos por sumersión y por otras causas de muerte, al correlacionar el peso de los pulmones y derrame pleural con el peso del bazo.

2.7. Oído medio. En el oído medio y en la región mastoidea pueden aparecer focos de infiltración hemorrágica que se transparentan a través del techo del peñasco con una coloración azulada muy característica. Niles [1 12] describió estas hemorragias en 23 de 24 ahogados en agua dulce, apareciendo en la mayor parte de los casos con carácter bilateral. Estas hemorragias están localizadas en la mucosa del oído medio y/o celdas mastoideas, y generalmente se acompañan de edema submucoso y congestión vascular. Para Knight [9/] es un signo poco fiable, pudiendo encontrarse en otras asfixias mecánicas e incluso en muertes naturales [1 I, 92, I1 3].

2.8. Sangre. Hemodilución. Si bien es cierto que los signos comunes a las asfixias mecánicas son menos abundantes en la sumersión que en otras variedades, sobre todo las equimosis internas y externas, la fluidez de la sangre suele ser mayor que en otras variedades de asfixia, debido probablemente al proceso de dilución [II]. La sangre contenida en las cavidades izquierdas del corazón, proveniente de la circulación pulmonar, está más diluida que la contenida en las cavidades derechas [89].

Resaltan Zangani et al [49] la utilidad práctica de la denominada "prueba cartohematométrica" para comparar la mayor dilución y menor densidad de la sangre del ventrículo izquierdo, respecto del derecho. Para ello, basta con depositar una serie de gotas de sangre de cada uno de los dos ventrículos, del mismo volumen y desde la misma altura, sobre un papel de filtro. La mayor dilución de la sangre del ventrículo izquierdo se pone de manifiesto con una más rápida y amplia difusión sobre el papel, una coloración menos intensa y márgenes más irregulares. La subjetividad en la apreciación de los resultados y su falta de sensibilidad han hecho que no sea una prueba de aplicación rutinaria, aunque podría aportar algún indicio cuando los resultados fueren manifiestamente objetivos.

Jeanmonod et al [ | | 4], calculan la dilución de la sangre de forma indirecta, al comparar el punto de congelación de la misma en ambos ventrículos, atendiendo a la fórmula siguiente:

$$
\begin{gathered}
\text { Hemodilución }(\%)=\frac{V_{D}-V_{I}}{V_{D}} \\
V_{D} \text { : Osmolaridad del ventrículo derecho }(\mathrm{mOsm} / \mathrm{L}) \text {. } \\
V_{1} \text { : Osmolaridad del ventrículo izquierdo }(\mathrm{mOsm} / \mathrm{L}) \text {. }
\end{gathered}
$$


Concluyen que los casos de sumersión tienen un valor medio de hemodilución $(9.33 \% \pm 8.18)$ más alto que los sujetos fallecidos por otras causas (I.28\% \pm 4.08$)$. No obstante, los resultados pueden ser influenciados por las transformaciones inducidas por la autolisis y la putrefacción, e incluso por las maniobras de reanimación que hubieran sido aplicadas, motivos por los cuales este marcador no se ha incorporado a la práctica de rutina.

Byard et al [ 1 I5] demuestran la existencia y la cuantía de la hemodilución midiendo las concentraciones de sodio en la sangre contenida en el ventrículo izquierdo, concluyendo que los ahogados en agua dulce presentan una significativa reducción de las concentraciones de sodio, que pone en evidencia la hemodilución. No han podido comprobar estos hallazgos en sujetos ahogados en agua salada.

2.9. Senos paranasales. Reh [ 108$]$ describió la presencia de agua en los senos paranasales, considerándola como una consecuencia más de la simple permanencia de los cadáveres en el agua, habida cuenta que podía penetrar postmortem. Hotmar [ I 16] detectó la presencia de líquido en los senos paranasales, esfenoidales o maxilares en el $75 \%$ de 387 ahogados en agua dulce, y en un solo caso del grupo control. Asimismo, Bohnert et al [1 17] han medido las cantidades de líquido contenido en el seno esfenoidal en ahogados y han comparado sus resultados con las cantidades apreciadas en sujetos fallecidos por otras causas. El 92\% de los ahogados tenían de I a 4 mL de líquido, pero también se obtuvieron resultados positivos en el 52\% del grupo control, si bien en cantidades menores.

Este signo puede ser observado con el examen radiológico de los senos paranasales [1|8], aunque la interpretación de los resultados ha de hacerse con las limitaciones ya expuestas $(*)$.

2.10. Tinción del tronco aórtico. La tinción hemoglobínica de la porción proximal de la aorta ha sido citada como un posible marcador de la sumersión en agua dulce $[119,120]$, consecutiva a la importante hemólisis que se produciría en estos casos. Byard et al [12I] dan cuenta de un caso de sumersión en agua dulce, afirmando que, si bien la tinción hemoglobínica de la íntima de la aorta es un signo inespecífico que sólo pone en evidencia la lisis de los hematíes, la tinción de la aorta proximal, pero no del tronco de la arteria pulmonar, sería un signo orientativo de sumersión en agua dulce. En otro trabajo más reciente, publicado en 2006, Byard et al [1 I5] comprueban experimentalmente en animales que la introducción de sangre hemolizada en el ventrículo izquierdo y embocadura de la aorta es capaz de provocar la tinción de la íntima. Concluyen que el hecho de encontrar la tinción en la aorta, pero no en el tronco de la pulmonar, sería la consecuencia lógica de la sumersión en agua dulce.

${ }^{*}$ ) Levy et al (2007), han publicado muy recientemente un artículo sobre autopsia virtual, aplicando la Tomografía Computarizada, con multidetector bi y tri-dimensional, para hacer un estudio comparativo de estos hallazgos con los obtenidos tras la práctica de la autopsia en los casos de sumersión. Los hallazgos de la Tomografía ponen de manifiesto la presencia de líquido espumoso en las vías respiratorias, así como una gran atenuación de la señal en las vías respiratorias por la presencia de sedimentos del líquido de sumersión. Asimismo, describen la presencia de líquido en los senos paranasales, celdas mastoideas, tráquea y bronquios, y opacidad deslustrada en los campos pulmonares (Levy $A D$, Harcke HT, Getz JM, Mallak CT, Caruso JL, Pearse L, Frazier AA, Galvin JR. Virtual Autopsy: Twoand Three-dimensional Multidetector CT findings in drowning with autopsy comparison. Radiology 2007; 243:862-868). 


\section{HALLAZGOS HISTOPATOLÓGICOS:}

Es clásico observar a nivel de los pulmones una distensión pseudoenfisematosa, descrita frecuentemente como "enfisema hidroaéreo", producida por el estiramiento, dilatación y ruptura de los tabiques alveolares, dando lugar a la formación de cavidades voluminosas, a menudo poligonales, con una disposición no sistematizada. La tinción selectiva de las fibras de reticulina muestran esta modificación estructural [46]. Una descripción más extensa de estas modificaciones puede encontrarse en Derobert [122].

El edema alveolar es casi constante, predominando en los sectores mejor conservados y ausente en las zonas de dilatación aguda. La congestión es notoria en las zonas menos distendidas. Pueden apreciarse también focos de hemorragia alrededor de los tabiques alveolares rotos.

Para Janssen [123], un importante hallazgo histológico en los pulmones es la dilatación aguda de los alvéolos con extensión, elongación y adelgazamiento de sus paredes y compresión de los capilares alveolares.

Shkrum y Ramsay [73] sistematizan los hallazgos microscópicos en los siguientes:

- "Enfisema acuoso", entendido como dilatación de alvéolos, adelgazamiento de la pared alveolar y compresión de los capilares alveolares.

- Congestión pulmonar, edema, hemorragia alveolar, ruptura de paredes alveolares.

- Los macrófagos alveolares pueden estar disminuidos en ahogados recientes, al ser arrastrados o lavados por el líquido de sumersión. En cadáveres en putrefacción, el número de macrófagos pulmonares puede ser muy variable.

- Hemorragia alveolar, la cual es significativa en los casos de sumersión sin putrefacción, y en muertes asfícticas comparadas con sujetos fallecidos por otras causas.

Algunos de estos hallazgos han sido descritos por muy diferentes investigadores, tras observaciones realizadas en animales de experimentación, empleando tanto la microscopía óptica como la miscrocopía electrónica [124, 125, 126, 127]. Se ha resaltado, asimismo, que aquellos signos tienen valor cuando los cambios autolíticos no están presentes en el cadáver [128, I29, 130]. Delmonte y Capelozzi [ 13 I] han intentado caracterizar tales hallazgos en los diferentes tipos de asfixias mecánicas, concluyendo que el análisis semicuantitativo de los hallazgos en el pulmón podría ser de utilidad como criterio complementario para fundamentar el diagnóstico de asfixia.

Además del estudio de los macrófagos alveolares [129, 130], se han estudiado, por métodos inmunohistoquímicos, diferentes subtipos de mielomonocitos (MRP8, MRPI 4 y 27E I0), formulándose una evaluación cuantitativa de los mismos en los espacios intraalveolar, alveolar/intersticial y alveolar/intracapilar, y poniéndose de manifiesto unos valores más altos en los casos de sujetos fallecidos por asfixia por sumersión que en los fallecidos por otras causas.

La microscopía electrónica, de barrido y de transmisión, ha sido aplicada en trabajos experimentales con animales, a efectos de demostrar los cambios histológicos producidos durante la sumersión [132, 133, 134]. Se ha comprobado una rápida hinchazón de las células epiteliales alveolares de tipo I y, posteriormente, de las células endoteliales alveolares, sufriendo menores cambios las células epiteliales de tipo II. En los casos de sumersión en agua salada, el principal cambio apreciado es el proceso de vacuolización que sufre el citoplasma de las células endoteliales alveolares [135].

Torre y Varetto [136] han descrito cambios similares en cadáveres de sujetos fallecidos por asfixia por sumersión (laceración de la pared alveolar, dilatación alveolar y compresión de los capilares), si bien no han podido comprobar modificaciones más sutiles y precisas, al solaparse con las variaciones inducidas por los cambios postmortem. 
Formuladas estas consideraciones, coincidimos con Saukko y Knight [137], cuando vienen a afirmar que los resultados de estas aplicaciones son confusos, a veces contradictorios y no siempre fáciles de interpretar, por lo que no resultan plenamente fiables.

Desde otro punto de vista, también se han realizado estudios histoenzimáticos del tejido cardíaco que han puesto de manifiesto una precoz desaparición de la actividad enzimática de la fosforilasa en sumersiones experimentales en conejos, tanto en agua dulce como con soluciones de suero fisiológico, sin observarse alteraciones de la citocromooxidasa, de la NADH diaforasa y de la lacticodeshidrogenasa [138]. Otros trabajos experimentales de este mismo grupo ponen en evidencia un incremento marcado de la CPK y menor de la GOT, sin apreciar diferencias significativas en la GPT, lo que consideran como consecuencia del daño selectivo producido en el parénquima pulmonar [139].

\section{EXÁMENES BIOLÓGICOS Y TANATOQUÍMICOS:}

El diagnóstico de certeza de una muerte por asfixia por sumersión es uno de los problemas de más compleja resolución en Patología Forense, para el que aún hoy no disponemos de un método o procedimiento diagnóstico cuyos resultados sean irrefutables. Puede afirmarse, como lo hacen Piette y De Letter [94], que el test diagnóstico ideal como prueba definitiva de asfixia por sumersión todavía está por ser establecido.

Los principios generales sobre los que se sustentan los diferentes procedimientos diagnósticos, complementarios a los resultados de la autopsia, se basan en las consecuencias inmediatas que origina el líquido de sumersión al introducirse en el organismo, haciendo penetrar, igualmente, los diferentes elementos químicos y partículas que se encuentran en el mismo.

\section{COMPONENTES QUÍMICOS:}

Carrara [140], en 1902, comprobó la dilución desproporcionada de la sangre contenida en el ventrículo izquierdo de ahogados en agua dulce frente a los ahogados en agua salada, determinando el peso específico, punto de congelación y conductividad eléctrica para diferenciar estos tipos de sumersión. Un año más tarde, Placzek [ $14 \mid$ ] insistía sobre el valor del peso específico a los mismos fines diagnósticos.

Años más tarde, Gettler [142] propone la medición de la concentración de cloruros en la sangre de las cavidades cardíacas izquierdas y derechas, cuyas concentraciones difieren en caso de sumersión vital, en un sentido inverso, según se trate de sumersión en agua dulce o en agua salada. Tras las publicaciones realizadas por Durlacher et al [1 43] y Fuller [63], el método fue abandonado, dada la escasa fiabilidad de los resultados. Moritz [144] intenta el uso del magnesio como marcador para la asfixia por sumersión, y Freimuth y Swann [145] proponen la medición de la densidad relativa (o gravedad específica) del plasma en la sangre de las cavidades izquierdas y derechas del corazón. Rivers et al [146] comprueban, en personas recuperadas tras sufrir un cuadro de sumersión, que la medida de los electrolitos no muestra un patrón regular, y Modell y Davis [147] llegan a afirmar que la medición de los electrolitos origina considerables dudas acerca de la fiabilidad de los resultados a los fines diagnósticos que venimos considerando.

Pese a ello, en los últimos años se han publicado numerosos trabajos en un intento de determinar un marcador bioquímico que resulte especialmente útil para el diagnóstico de la asfixia por sumersión. Sin ánimo de ser exhaustivos, podemos citar el trabajo de Lorente et al [148], en el que, entre otros elementos, estudian la osmolaridad del plasma, así como las concentraciones de cloro, magnesio y potasio. Yu-Chuan et al [1 49] estudian las concentraciones de flúor, y Jeanmonod et al [ I l 4], determinan los valores del punto de congelación de la sangre contenida en ambos ventrículos. 
El grupo de investigación de Zhu et al [150] ha estudiado el comportamiento de las concentraciones de cloro, sodio, calcio, magnesio, urea y creatinina en la sangre de ambos ventrículos de sujetos ahogados, tanto en agua dulce como en agua salada, comparándolas con los resultados obtenidos en otros tipos de muerte, y estiman que dichos resultados son útiles para diferenciar ambos grupos y también para precisar si la sumersión se produjo en agua dulce o salada, siempre que las determinaciones se lleven a cabo muy precozmente. En otra publicación [15 I] determinan las concentraciones de calcio y magnesio, a los que encuentran útiles para diferenciar si la sumersión se llevó a cabo en agua dulce o salada. La troponina T también ha sido estudiada por Zhu et al [152], en suero y en líquido pericárdico, y los resultados obtenidos les permiten asegurar que este marcador no sólo puede ser utilizado para el diagnóstico del infarto de miocardio, sino que también puede ser de gran ayuda para diferenciar los cuadros de infarto de los de sumersión y de graves hipotermias. En su más reciente trabajo, publicado en 2007, Zhu et al [ I53] han estudiado las concentraciones de urea, creatinina y ácido úrico en sangre y en líquido pericárdico. En los casos de sumersión, y con independencia de que se trate de agua dulce o salada, encuentran unos valores bajos en la concentración de urea en la sangre del corazón izquierdo y en el líquido pericárdico, al compararlos con los obtenidos en el corazón derecho y en sangre periférica, lo que atribuyen a la dilución de la sangre de las venas pulmonares en el corazón izquierdo debido a la entrada de agua. Por ello, en opinión de estos autores, una ratio alta entre las concentraciones del corazón derecho y sangre venosa periférica respecto al líquido pericárdico puede ser utilizada como marcador para el diagnóstico de la sumersión.

Señalemos, finalmente, que De La Grandmaison et al [154] han estudiado las concentraciones de hierro en la sangre contenida en las cavidades derechas e izquierdas del corazón, encontrando diferencias significativas en casos de sumersión en agua dulce, por lo que estiman que pueden ser un buen marcador para el diagnóstico de la sumersión, siempre que el intervalo postmortem sea de corta duración.

Nos ocuparemos, por último, de las investigaciones realizadas sobre el estroncio que, posiblemente, es el marcador exógeno más estudiado en la asfixia por sumersión. Como ya se ha indicado, al penetrar el líquido de sumersión en la circulación sanguínea hace penetrar también a todos aquellos elementos químicos y partículas que se encuentren en el mismo. Como recuerdan Piette y De Letter [94], al referirse a los requisitos que debe cumplir un buen marcador para ser aplicado al diagnóstico de la muerte por sumersión,....

- el marcador debe tener la posibilidad de atravesar la membrana alveolo-capilar y penetrar en la circulación.

- el marcador debe estar presente en grandes cantidades en el medio de sumersión y en muy pequeñas cantidades en la sangre de personas sanas. La ratio del estroncio en agua de mar y suero (650: I) hace de él un potencial marcador para el diagnóstico de la asfixia por sumersión [74], y ello a pesar de las diferentes concentraciones que pueden observarse entre distintos puntos geográficos.

- el marcador no debe penetrar en la circulación a través de otras vías (aparato digestivo) o por fenómenos de difusión postmortem.

Este modelo teórico, señalado ya por Icard [ I55], fue utilizado por Abdallah et al [I56] en animales de experimentación (conejos), concluyendo que la determinación del estroncio en suero era útil para determinar el carácter vital de una sumersión, así como para diferenciar si la sumersión se había producido en agua dulce o agua salada. Señalaron también que los niveles de estroncio no se veían afectados por maniobras de reanimación, ni por la hemólisis, ni por los cambios inducidos 
precozmente por la putrefacción. Estos extremos también fueron puestos en evidencia por Piette, Timperman y Parisis [157] en cadáveres recuperados del agua, afirmando que la investigación de este marcador puede ser una prueba adicional válida para el diagnóstico de la sumersión en agua salada [I58]. También se han señalado algunas circunstancias a considerar para la valoración de un caso concreto, tales como que algunos tipos de agua tienen una baja concentración de estroncio (agua de lluvia, agua de consumo doméstico) y el hecho de que los consumidores habituales de algunos tipos de agua mineral o los consumidores habituales de alimentos de origen marino, pueden tener unas tasas elevadas de este elemento en sangre $[159,160]$.

Uno de los grupos de investigación más activos en relación con este marcador es el liderado por Azparren, el cual demostró que, en los casos de asfixia por sumersión ("típicos"), en agua salada, las diferencias entre las concentraciones de estroncio entre la sangre del ventrículo izquierdo y el derecho son superiores a $75 \mu \mathrm{g} / \mathrm{L}$ [16 I]; estos resultados fueron ratificados en una publicación posterior [162], resaltando el valor de este marcador cuando las concentraciones de estroncio en el medio de sumersión son superiores a $800 \mu \mathrm{g} / \mathrm{L}$. A conclusiones similares llegan Fornes et al [128], tras comparar las concentraciones de estroncio en 1 I 6 sujetos ahogados, con 35 fallecidos por causas no asfícticas y 23 sujetos vivos sanos. Los valores medios de estroncio en sangre fueron mucho más altos que en los controles, no apreciando solapamiento alguno entre sujetos ahogados y no ahogados, como previamente habían señalado otros autores [156].

Nuevas publicaciones de Azparren et al [163] ponen en evidencia que las diferencias en las concentraciones de estroncio entre ambos ventrículos puede estar condicionada por la duración de la agonía.

En otros trabajos, Azparren et al [164], tras revisar un total de 144 cadáveres que habían sufrido un cuadro de sumersión en agua dulce, comprueban que en el $32 \%$ de los casos la medición del estroncio podría permitir el diagnóstico de asfixia por sumersión con un razonable grado de confianza. Nuevos trabajos, aún pendientes de publicación, centran la atención de Azparren et al $[165,166]$, en la relación de los niveles de estroncio con la edad y el sexo de las víctimas, y con la temperatura del agua, así como con el peso de los pulmones.

Pérez-Cárceles et al [167], tras estudiar los niveles de estroncio en 82 cadáveres, fallecidos por asfixia por sumersión [23], otras asfixias mecánicas [33] y otras muertes no asfícticas [26], concluyen, asimismo, que este marcador puede ser usado para el diagnóstico de las muertes por sumersión, y para diferenciar si ésta se ha llevado a cabo en agua dulce o en agua salada. Asimismo, se han correlacionado los niveles de estroncio con la proteína A del surfactante pulmonar en diferentes causas de muerte [168].

\section{MARCADORES BIOLÓGICOS EN LA SUMERSIÓN:}

Como ya se ha indicado en líneas precedentes, durante el proceso de la sumersión y tras la penetración del agua se van a producir lesiones en las membranas alveolares, a través de las cuales van a pasar a la circulación sanguínea, tanto el medio de sumersión como las pequeñas partículas que se encuentran en suspensión en el mismo. Este hecho ha sido comprobado en animales de experimentación utilizando marcadores de látex, detectados mediante microscopía de fluorescencia, y marcadores de oro, empleando microscopía electrónica [169], demostrándose que los marcadores con diámetros pequeños penetraban en los espacios intercelulares del epitelio alveolar.

Los primeros trabajos basados en aquel principio se deben a Corin y a Stockis [170, 17I, 172], quienes estudiaron los elementos cristalinos presentes en el líquido de sumersión. Las dificultades en la identificación de los mismos condicionó el pronto abandono de estos procedimientos. 
La atención de los investigadores se dirigió entonces al estudio de las diatomeas, el cual gozó inicialmente de una gran aceptación en la comunidad científica, si bien comenzaron a surgir críticas y dudas que aún hoy persisten. Puede afirmarse que tras la primera descripción de las diatomeas en 1904 por Revenstorf [173], se han sucedido un gran número de publicaciones, en torno a la aplicación de las diatomeas en el diagnóstico de la muerte por sumersión, entre las que hemos de destacar las monografías de Ludes y Coste [174] y de Pollanen [I75], así como la amplia revisión realizada sobre esta particular cuestión por Lunetta y Modell [74].

Como es bien conocido, las diatomeas son algas celulares eucarióticas (Bacillariophyceae), que se encuentran presentes tanto en el agua dulce como en el agua salada, así como en la tierra y en el aire. El tamaño de las mismas varía desde $2 \mu \mathrm{m}$ a más de $500 \mu \mathrm{m}$, midiendo la mayoría de las especies entre 10 y $80 \mu \mathrm{m}$ de longitud o de diámetro. La pared celular contiene una alta cantidad de sílice, denominándose "frústula" a la parte silícea entera de la diatomea o exoesqueleto, el cual es duro y resistente a la descomposición y a la acción de ácidos fuertes.

Las diatomeas pueden clasificarse atendiendo a muy diferentes criterios, siendo de especial interés en Medicina Forense, además de la clasificación taxonómica, la clasificación basada en la salinidad del medio en el que se desarrollan (oligofílicas, mesohalofílicas y polihalofilicas, según la salinidad sea menor de $0.05 \%$, se trate de agua salobre o sea superior a $0.05 \%$, respectivamente). Dada la extraordinaria variabilidad de las mismas, el análisis no resulta especialmente fácil, siendo necesario el concurso de un especialista para su adecuada valoración [176, 177].

La aplicación de las diatomeas para el diagnóstico de la asfixia por sumersión se basa en el hecho de que penetrarían en los pulmones conjuntamente con el líquido de la sumersión, y si el sujeto se encuentra vivo, con actividad cardiocirculatoria eficaz, atravesarían el filtro pulmonar y se diseminarían por todo el organismo a través del torrente circulatorio, pudiendo identificarlas en médula ósea, hígado, cerebro o riñones. Si se tratara de un cadáver arrojado o caído al agua, las diatomeas podrían penetrar de forma pasiva en el aparato respiratorio, pero no podrían llegar a otros órganos al no existir actividad circulatoria.

Este planteamiento tan simple no ha estado exento de debate, existiendo argumentos a favor y en contra de la utilidad de estos marcadores para el diagnóstico de la asfixia por sumersión [|78-|8|]. Es necesario resaltar que las diatomeas no han podido ser identificadas en todos los cadáveres, habiéndose conseguido su identificación en sólo un tercio de cadáveres que han sufrido un cuadro de asfixia por sumersión en agua dulce [182- | 84], estimándose por algunos que en mar abierto tampoco se comportarían como un marcador fiable [185].

Por el contrario, Tomonaga [186] y Navikawa y Kotoku [187] identificaron diatomeas en sujetos fallecidos por otras causas distintas a la asfixia por sumersión, pero que habían permanecido en el agua. Ello condujo a Reh [108] a afirmar que la mera identificación de las diatomeas en los pulmones es un hallazgo inespecífico, tal como con anterioridad habían afirmado Neidhart y Greendyke [188]. Pese a todo, Timperman [189] interpreta el hallazgo de las diatomeas en el pulmón como signo indicativo de muerte rápida en el agua, puntualizando Auer y Möttönen [190], que dicho indicio tendría un evidente valor diagnóstico si se identifican más de 20 diatomeas por campo en muestras de pulmón. Este criterio cuantitativo no es suficiente para otros autores [174], al estimar que la presencia de diatomeas en los pulmones, pero no en otros órganos de la economía, no permite excluir la posibilidad de una penetración pasiva.

Lunetta et al [|9|], empleando miscrocopía electrónica de barrido y de transmisión, han demostrado la penetración de las diatomeas desde los alvéolos al torrente circulatorio, así como su fagocitosis por macrófagos alveolares. No todas las diatomeas presentes en el líquido de sumersión 
son capaces de atravesar la barrera alveolo-capilar, lo cual viene condicionado, en gran medida, por el tamaño de aquéllas y por el hecho de su posible agregación en grupos o colonias. Como ya se ha indicado, el tamaño de las diatomeas es muy variable y los datos disponibles acerca de las que tendrían la capacidad de atravesar la barrera alveolo-capilar son contradictorios [186, I 87]. Lunetta y Modell [74], llegan a afirmar que la falta de protocolos estandarizados para el análisis cuantitativo y cualitativo de las diatomeas hace prácticamente imposible cualquier comparación entre diferentes estudios.

En la exhaustiva revisión que hacen Lunetta y Modell [74] de la asfixia por sumersión, dedican especial atención al estudio de las diatomeas, y en éste, se ocupan con detenimiento de las principales causas de error de este test diagnóstico. Siguiendo su propio esquema, distinguiremos entre:

A) Falsos resultados positivos. La principal crítica que puede hacerse al estudio de las diatomeas es el hallazgo de éstas en pulmones y otros órganos de personas fallecidas por causas distintas a la sumersión, lo cual puede reconocer muy diversos orígenes.

\section{A. I. Contaminación antemortem:}

- Ingestión de vegetales con alto contenido en diatomeas (lechuga, berros, apio).

- Ingestión de mariscos con alto contenido en diatomeas (mejillones, ostras, bígaros)

- Ingestión de bebidas (cerveza, vino), en cuyo proceso de elaboración se emplea sílica gel como material de filtración.

- Inhalación de diatomeas en las fábricas de materiales de construcción y de aislantes.

- Inhalación de diatomeas al fumar cigarros, ya que las hojas del tabaco las contienen.

- Inhalación de diatomeas en suspensión en el aire.

\section{A.2. Penetración postmortem:}

- Sumersión prolongada en el agua a alta presión hidrostática.

- Penetración en cadáveres sumergidos, a través de heridas producidas en vida.

- Penetración durante la aplicación de maniobras de reanimación con ventilación artificial, en cadáveres recuperados del agua.

A.3. Contaminación durante la preparación de las muestras:

- Contaminación por las ropas del cadáver.

- Contaminación durante la ejecución de la autopsia.

- Contaminación a través de instrumental y materiales utilizados en la autopsia.

- Contaminación por el agua y reactivos.

- Contaminación del material de vidrio utilizado.

A.4. Otras fuentes de contaminación:

- Inhalación de agua por buceadores o nadadores.

- Paso transplacentario de las diatomeas.

- Contaminación del páncreas y vesícula biliar por el paso retrógrado del contenido del duodeno.

- En casos de exhumación, contaminación postmortem por el serrín que eventualmente pueda existir en el ataúd. 


\section{B) Falsos resultados negativos:}

- Baja concentración de diatomeas en el medio de sumersión.

- Escasa cantidad de líquido inhalado.

- Pérdida de diatomeas durante el proceso de preparación de las muestras.

Es necesario insistir en que la baja concentración de diatomeas en el medio de sumersión puede ser determinante a la hora de realizar este tipo de investigación [1 85, 192], circunstancia ésta que puede verse favorecida por la contaminación ambiental de las aguas superficiales [189]. De otra parte, es necesario tomar en consideración que las diatomeas no se encuentran en cantidades importantes en el agua durante todo el año, sino que sufren variaciones estacionales o climáticas, siendo más abundantes en primavera y en otoño.

Otra de las causas de error podría radicar en el empleo de técnicas inadecuadas para una correcta recuperación de las diatomeas a partir de las muestras de tejidos u órganos en los que se vaya a llevar a cabo la investigación. Las técnicas de extracción requieren la destrucción previa de la materia orgánica, para lo cual se ha empleado la digestión química con ácido nítrico o sulfúrico [ 174 , 193], solubilizantes como el Solueno-350 [194, 195], el cual no es recomendable para las diatomeas en agua salada, o enzimas como la proteinasa $\mathrm{K}$ con el dodecil-sulfato-sódico [196].

El método de reacción en cadena de la polimerasa (PCR) ha venido a proporcionar nuevas perspectivas en la identificación de las diatomeas por medio de primers para genes relacionados con la clorofila [197, 198, 199], y constituye un método alternativo a los que tradicionalmente se venían utilizando con ácidos fuertes, los cuales pueden resultar sumamente agresivos para las diatomeas en agua salada [200]. La alta sensibilidad de estas nuevas técnicas conlleva también un mayor riesgo de contaminación.

Para terminar con estos marcadores es necesario tomar en consideración que cualquier investigación que se pretenda llevar a cabo con ellos requiere no sólo el análisis cualitativo y cuantitativo de las diatomeas en los diferentes órganos y tejidos, sino también el obligado estudio comparativo con el análisis de las diatomeas en el medio en el que se ha producido la sumersión.

La toma de muestras de agua debe llevarse a cabo al mismo tiempo que se produce la recuperación del cadáver, registrando la temperatura del agua. Deben tomarse muestras de agua de la superficie y a diferentes profundidades, utilizando para ello recipientes estériles de un litro de capacidad. Las muestras recogidas se mantendrán a $41^{\circ} \mathrm{C}$ hasta el momento de su manipulación.

En el transcurso de la autopsia, y con todas las recomendaciones formuladas anteriormente para evitar la contaminación, se tomarán muestras de sangre de ambos ventrículos y de vena femoral, así como muestras de diferentes órganos (hígado, riñón, cerebro y médula ósea).

Para obviar algunos de los inconvenientes de este método, Peabody y Burgess [20 I], estiman que su estudio resultaría de utilidad si se cumplen las siguientes condiciones:

- Los riesgos de contaminación durante el proceso analítico deben ser reducidos al mínimo. El material de vidrio utilizado debe estar escrupulosamente limpio y los reactivos han de ser de gran pureza.

- Todas las diatomeas que pueden haber estado en el organismo durante la vida deben ser identificadas y excluidas para el diagnóstico.

- Deben encontrarse especies similares de diatomeas en los pulmones y en el resto de los órganos.

Igualmente, y a efectos de evitar interpretaciones erróneas, Hürlimann et al [177] recomiendan que el estudio de las diatomeas incluya: 
- Estudio cuantitativo de las diatomeas.

- Determinación de las especies.

- Morfometría de las especies identificadas.

Lunetta y Modell [74], concluyen que para considerar que los resultados son aceptables han de cumplirse las siguientes premisas:

A. Concordancia taxonómica, cualitativa y cuantitativa, entre las diatomeas encontradas en el cuerpo y en el medio de sumersión.

B. Adopción de un estricto protocolo para evitar la contaminación durante todo el proceso de preparación de las muestras.

C. Exclusión de los resultados de cualesquiera diatomeas que potencialmente puedan ser "contaminantes".

Un método alternativo a la investigación de las diatomeas ha sido la identificación de los protozoos ciliados en sangre, propuesto por Chardez y Lambert [202], para los cadáveres de sujetos ahogados en agua dulce. Realizan la identificación de protozoos ciliados del género Tetrahymena, a través del cultivo de muestras de sangre, ya que poseen una extraordinaria capacidad de reproducción.

Como complemento al estudio de las diatomeas, y sobre todo cuando se trata de aguas dulces pobres en diatomeas, se ha propuesto el estudio de las algas verdes [203], empleando el Solueno-350 para solubilizar los tejidos, el cual permite la detección, no sólo de las diatomeas, sino también la de las algas verdes, ya que dicho disolvente no digiere las paredes de las células de las algas verdes, las cuales están constituidas por celulosa. Se ha propuesto en la determinación del diagnóstico de la sumersión el análisis de la clorofila del plancton en muestras de pulmón con un espectrofluorofotómetro [204]. Las algas verdes también han sido utilizadas para el establecimiento del intervalo postmortem en cadáveres sumergidos [205, 206].

En 1990, Mishul’skii [207], propuso el análisis bacteriológico de la sangre de cadáveres recuperados del agua para el diagnóstico de la asfixia por sumersión. La investigación la llevó a cabo en muestras de sangre femoral en sujetos ahogados y en fallecidos por otras causas como grupo control, comprobando que la Ps. putida y la Ps. fluorescens, que no estaban presentes en la sangre de los sujetos del grupo control, podían ser utilizadas como test bacteriológico.

En el presente año, Lucci y Cirnelli [208] han publicado los resultados de un estudio llevado a cabo en 42 ahogados, tanto en agua dulce como en agua salada, y en 30 sujetos fallecidos por otras causas. Han estudiado la presencia de bacterias típicas de contaminación fecal de las aguas (Estreptococo fecal y Coliformes fecales), en la sangre de ambos ventrículos, arteria femoral y vena femoral. El Estreptococo fecalis está presente en la sangre del ventrículo izquierdo en el $100 \%$ de los ahogados, tanto en agua dulce como en agua salada. Señalan dichos autores que la sensibilidad del método podría dar resultados positivos aunque se hubiesen inhalado muy pocos gérmenes, reconociendo, asimismo, que esa alta sensibilidad representa un riesgo real de falsos resultados positivos debido a la posibilidad de contaminación durante la toma de las muestras.

\section{COMPONENTES ALVEOLARES QUE PUEDEN SER ENCONTRADOS EN LA CIRCULACIÓN GENERAL:}

Siguiendo a Piette y De Letter [94], diferenciamos este grupo de marcadores, dado el origen de los elementos a investigar, los cuales serían removidos de su asentamiento habitual por el líquido de sumersión, pasando a la circulación general tras la ruptura de las paredes alveolares [130]. 
Si bien ya nos hemos referido con anterioridad al estudio de los macrófagos alveolares, estimamos pertinente hacer mención específica de los trabajos realizados por Reiter [209], quien puso de manifiesto la presencia de células de fumadores en la sangre del ventrículo izquierdo en las víctimas de asfixia por sumersión, resaltando el interés de estas investigaciones en los casos de muerte en la bañera, dada la escasez de plancton existente en el agua de la red de suministro, y con la lógica limitación de que sólo podría aplicarse a los fumadores activos. Son escasas las publicaciones sobre este tipo de marcador.

Por el contrario, el estudio del surfactante pulmonar ha sido objeto de consideración por parte de diferentes grupos de investigación. El surfactante pulmonar es un complejo lipoproteínico, sintetizado principalmente por las células epiteliales alveolares tipo II, que reduce la tensión superficial en la interfase aire-líquido. Existen cuatro proteínas específicas del surfactante, dos de las cuales son hidrofilicas (SP-A y SP-D) y otras dos de carácter hidrofóbico (SP-B y SP-C), cuyo significado funcional no es bien conocido.

Giammona y Modell [59] habían demostrado los efectos de la sumersión en agua dulce y en agua salada sobre el surfactante pulmonar, siendo las consecuencias de aquélla más intensas y evidentes en los casos de sumersión en agua dulce. Lorente et al [2। 0] estudiaron las modificaciones de los fosfolípidos del surfactante (fosfatidilcolina, fosfatidiletanolamina y fosfatidilglicerol), en conejos ahogados en agua dulce y en agua salada, comprobando que en las muestras de lavado endobronquial las concentraciones de aquéllos diferían sensiblemente entre los animales ahogados y los fallecidos por otras causas (grupo control). Los cambios eran menos acusados cuando se investigaban los fosfolípidos en muestras de pulmón, posiblemente debido a una mayor concentración de fosfolípidos almacenado en el tejido pulmonar. En otra publicación daban a conocer que habían comprobado experimentalmente en ratas, la estabilidad postmortem de los fosfolípidos durante las primeras 24 horas, seguida de una progresiva disminución a partir de las 48 horas y hasta las 96 horas postmortem [21 I].

Kamada et al [2/2] han estudiado la proteína D del surfactante pulmonar en ahogados, cuyos niveles se encontraron elevados, tanto en los casos de agua dulce como de agua salada, siendo más altos en este último caso. Por su parte, Zhu et al [2।3] han estudiado la proteína A del surfactante pulmonar (SP-A) en un total de 282 cadáveres autopsiados, de los que 59 habían fallecido por asfixia por sumersión. La inmunotinción más intensa y densa del SP-A se observó en los casos de ahogados, síndrome de las membranas hialinas y en casos de aspiración perinatal del líquido amniótico. En otra publicación [2|4], han evaluado los niveles séricos de SP-A y su distribución pulmonar en casos de ahogados en agua dulce y en agua salada, comprobándose que en los casos de sumersión en agua dulce existía una mayor acumulación granular intraalveolar, extremo éste también comprobado por otros autores [168].

Ishida et al [2I5] han hecho estudios sobre los genes SP-AI y SP-A2, mediante PCR, comprobando que la ratio SP-AI/SP-A2 fue notablemente más alta en los casos de asfixias por sumersión y otros mecanismos asfícticos, que en otros mecanismos de muerte. A conclusiones similares han llegado Maeda et al [2/6], quienes han comprobado también un aumento en SP-A intraalveolar granular y en la ratio de ARNm de SP-AI/SP-A2 en más del 75\% de ahogados en agua dulce y en los casos de distress respiratorio agudo, por lo que este marcador puede resultar sumamente útil como marcador para los casos de asfixias, distress respiratorio y daño alveolar.

En otra publicación de Zhu et al [150], a la que ya hemos hecho referencia, han encontrado una concentración de SP-A sérica significativamente elevada en ahogados en agua dulce, pero los resultados se solapan con los obtenidos en los casos de sumersión en agua salada y en los fallecidos por infarto agudo de miocardio. 


\section{OTROS MARCADORES:}

El péptido natriurético auricular (ANP) fue estudiado por Anderson et al [2/7], quienes comprobaron que, durante la inmersión en agua termoneutral en el hombre, las concentraciones plasmáticas del ANP se elevaban considerablemente, del mismo modo que se producía una elevada eliminación urinaria del sodio. Lorente [2। 8] realiza un trabajo experimental en conejos, concluyendo que la determinación del ANP es útil para establecer el diagnóstico de la sumersión vital y para el diagnóstico diferencial entre la sumersión en agua dulce y en agua salada. Asimismo, comprobaron la estabilidad postmortem de este marcador [2।9], proclamando su validez como marcador para el diagnóstico de la asfixia por sumersión.

Recientemente, en 2007, Zhu et al [220] han realizado una revisión de 263 cadáveres autopsiados, de los cuales, un total de 14 casos correspondían a asfixia por sumersión (agua dulce, 8; agua salada, 6). Han estudiado el péptido natriurético auricular (ANP) y el péptido natriurético cerebral (BNP) en el líquido pericárdico. Señalan en sus resultados una significativa elevación de los niveles de ANP, en contraste con el leve aumento que sufre el BNP, tanto en los ahogados en agua dulce como en agua salada, lo que puede abrir una nueva línea de investigación en relación con estos marcadores para el diagnóstico de la asfixia por sumersión.

Quan et al [22I] han estudiado la ubicuitina (HSP, Heat Shock Protein) en las neuronas de la "substantia nigra", mediante métodos inmunohistoquímicos, en diferentes tipos de asfixias mecánicas. La tinción difusa de este marcador fue más frecuentemente observada en los casos de asfixia por sumersión, aunque también concedió resultados positivos en el resto de las asfixias mecánicas, como corresponde a la situación de estrés a la que es sometido el sistema nervioso central, tanto en la asfixia por sumersión como en el resto de las asfixias violentas.

En algunos casos muy concretos podría hacerse uso también de eventuales contaminantes del medio de sumersión, los cuales se incorporarían a los órganos de la víctima, tras la correspondiente inhalación del líquido de sumersión al que contaminan. En este sentido pueden citarse las observaciones realizadas por Lehmann y Beuthin [222], quienes investigan la presencia de lignosulfato sódico, las determinaciones realizadas por Concheiro [ $\mathrm{l}$ l], investigando la presencia de taladrina en un caso de la práctica y la investigación llevada a cabo por Mukaida et al [223], determinando la presencia de sales de baño en el pulmón y riñones de un bebé ahogado en una bañera.

\section{DATA DE LA SUMERSIÓN:}

El diagnóstico del tiempo de permanencia del cadáver en el agua sigue constituyendo hoy un complicado problema, para el que no disponemos de respuestas concretas, debiendo pronunciarnos siempre dentro de amplios límites.

En términos generales, la determinación de la data de la sumersión se basa en la valoración del estado evolutivo en el que se encuentren los fenómenos cadavéricos y en los cambios inducidos por las fases más tempranas de la putrefacción cadavérica, siendo preciso puntualizar que, en algunos casos, podrá no coincidir la data de la sumersión con la data de la muerte.

No es necesario insistir en que aquellos cambios están fuertemente condicionados por la temperatura del medio de sumersión en el que se encuentre el cadáver, siendo bien conocido que a temperaturas bajas los fenómenos destructivos del cadáver se enlentecen.

Se han elaborado diferentes tablas, haciendo una evaluación global de la data a partir de las diferentes manifestaciones o signos que puedan apreciarse externamente en el cadáver, resultando ya clásica la tabla de Devergie [224], en la que aquellos signos y su correspondiente data eran diferenciados, según se tratara de meses de invierno o de verano. 
Más recientemente, se introdujo la tabla de datos tanatológicos propuesta por Reh [225], elaborada a partir del estudio de 395 cadáveres extraídos del agua, en la que los diferentes signos son valorados de forma diferenciada en cada uno de los meses del año, haciendo especial mención de la temperatura media del agua en cada uno de ellos. En esta tabla se valoran parámetros tales como los cambios cromáticos de la piel, el desarrollo de gases de la putrefacción, manifestaciones de la maceración de la piel, desprendimiento de la epidermis, cabellos y uñas, etc. Es necesario tomar en consideración que los plazos señalados en la misma pueden verse acortados si la sumersión se ha producido en aguas con temperaturas más templadas. Este mismo autor ha confeccionado unos diagramas de correlación de los datos anteriores [226].

Se ha propuesto otro procedimiento por Bray [227], consistente en medir las concentraciones de potasio y de cloro en el humor vítreo, haciendo el cálculo del intervalo postmortem, según la siguiente fórmula:

$$
\operatorname{PMI}(\text { días })=\frac{100 \mathrm{mEq} / \mathrm{L}+2\left[\mathrm{~K}^{+}\right]-[\mathrm{Cl}]}{10}
$$

El propio autor limita la aplicación de la misma a los casos en que la sumersión se lleve a cabo en aguas frías y que el intervalo postmortem sea superior a un día, con un margen de error inferior a 0.5 días. Asimismo, señala que los efectos de la temperatura hacen inaplicable la fórmula a los casos de sumersión en meses de verano. Para otros autores [46], el empleo del humor vítreo, a estos efectos, no es recomendable en los casos de sumersión, ya que se produce una difusión rápida del medio de sumersión a través de los tejidos corneales y conjuntivales.

Además del estudio de las algas en cuerpos sumergidos [205, 206], a las que nos hemos referido en líneas anteriores, se ha intentado aplicar también el estudio del grado de desarrollo de larvas de mosquitos (Chironomidae), como indicador del tiempo postmortem [228, 229], con los mismos principios básicos por los que se regulan los trabajos sobre la entomología cadavérica. Los resultados obtenidos con el estudio de estos insectos no son muy alentadores, como tampoco las observaciones realizadas sobre invertebrados acuáticos [230], razón por la cual esta línea de investigación no ha sido muy desarrollada.

Señalemos, finalmente, que la saponificación de los cadáveres, cuando ésta es evidente, también se ha intentado aplicar a la determinación de la data de la sumersión, aunque, dada la gran variabilidad de plazos en el inicio y desarrollo de este proceso conservador, que depende de múltiples factores y circunstancias, el pronunciamiento sólo puede establecerse dentro de unos amplios márgenes.

\section{BIBLIOGRAFÍA:}

I. Davis JH. Bodies found in the water. An investigative approach. Am J Forensic Med Pathol 1986; 7: 291-297.

2. Roll HF. Leerboek der Gerechtelijke Geneeskunde voor de scholen tot opleiding van Ind artsen. Martinus Nijhoff.' s-Gravenhage. 1918. 3. Modell JH. Drown versus near-drown: A discussion of definitions. Crit Care Med 1981; 9: 351-352.

4. Fields Al. Near drowning in the paediatric population. Crit Care Clin 1992; 8: II3-129.

5. Olshaker JS. Near drowning. Environ Emerg 1992; 10: 339-350. 6. Hasibeder W, Schobersberger W. Near drowning. En: E Søreide, CM
Grande (Editors), Prehospital trauma care. I. Marcel Dekker. New York. 2001. 603-614.

7. Van Dorp JC, Knape, JT, Bierens JJ. Recommendations: World Congress on Drowning, 2002. Amsterdam, The Netherland. ( http://www.drowning.nl/. 2003).

8. Idris AH, Berg RA, Bierens J et al. Recommended guidelines for uniform reporting of data from drowning: The Utstein style. Resuscitation 2003; 59: 45-57.

9. Beeck EF, Branche CM, Szpilman D, Modell JH, Bierens JJ. A new definition of drowning: Towards documentation and prevention of a global public health problem. Bulletin WHO 2005; 83: 853-856. 
10. Papa L, Hoelle R, Idris A. Systematic review of definitions for drowning incidents. Resuscitation 2005; 65: 255-264.

II. Concheiro Carro L, Suárez Peñaranda JM. Asfixias mecánicas. In: E Villanueva (Ed), Medicina Legal y Toxicología. 60 edición. Masson. Barcelona. 2004. 460-478.

12. Salomez F, Vincent JL. Drowning: a review of epidemiology, pathophysiology, treatment and prevention. Resuscitation 2004; 63: $261-268$.

13. De Nicola LK, Falk JL, Swanson ME, Gayle MO, Kissoon N. Submersion injuries in children and adults. Crit Care Clin 1997; 13: 477-502.

14. World Health Organization. Fact sheet on drowning. (On line: www.who.int/violence prev .

15. Mulligan-Smith D, Pepe PE, Branche CM. A seven-year statewide study of the epidemiology of pediatric drowning deaths. Acad Emerg Med 2002; 9: 488-489.

16. Blum C, Shield J. Toddler drowning in domestic swimming pools. Injury Prevention 2000; 6: 288-290.

17. Browne MI, Lewis EL, Stark AD. Unintentional drowning among New York State residents 1988-1994. Public Health reports 2003; II8: 448-458.

18. Golden FC, Tipton MJ, Scott RC. Immersion, near-drowning and drowning. Brit J Anesth 1997; 79: 214-225.

19. Siber JR, Lyons RA, Smith BA et al. Preventing deaths by drowning in children in the United Kingdom: have we made progress in 10 years? Population based incidence study. Brit Med J 2002; 324: 1070-1071.

20. Gorniak JM, Jenkins AJ, Felo JA, Balraj E. Drug prevalence in drowning deaths in Cuyahoga County, Ohio. A ten year retrospective study. Am J Forensic Med Pathol 2005; 26: 240-243.

21. Kringsholm B, Filskov A, Kock K. Autopsied cases of drowning in Denmark 1987-1989. Forensic Sci Int 1991; 52: 85-92.

22. Cairns F], Koelmeyer TD, Smeaton WMI. Deaths from drowning. The New Zealand Med J 1984, 97: 65-67.

23. Romero Palanco JL, Gamero Lucas JJ. El suicidio consumado en el Partido Judicial de Huelva. Cuad Med Forense 2005; II: 5-9.

24. Romero Palanco JL, Gamero Lucas J], Martínez García P. Aspectos epidemiológicos del suicidio consumado en la provincia de Cádiz (1999-2003). Cuad Med Forense 2007; I3: I-I2.

25. Romero Palanco JL. Aspectos epidemiológicos del suicidio en la Ciudad de Sevilla, referidos a los años de 1953 a 1977. Rev Esp Med Legal 1985; 12: 35-54.

26. Romero Palanco JL, Gamero JJ, Vizcaya MA, Arufe MI, Hernández A. Evolución del suicidio consumado en la Ciudad de Sevilla en los años de 1978 a 1987. Rev Esp Med Legal 1989; 16 (58/59): 9-21.

27. Byard RW, Houldsworth G, James RA, Gilbert JD. Characteristic features of suicidal drownings. A 20 year study. Am J Forensic Med Pathol 2001; 22: 134-138.

28. Avis SP. Suicidal drowning. J Forensic Sci 1993; 38: 1422-1426.

29. Davis LG. Suicidal drowning in South Florida. J Forensic Sci 1999; 44: 902-905.
30. Copeland AR. Suicide by drowning. Am J Forensic Med Pathol 1987; 8: 18-22.

31. Copeland AR. Homicidal drowning. Forensic Sci Int 1986; 31: 247-252.

32. Copeland AR. Homicide in childhood: The Metro-Dade County experience from 1956 to 1982. Am J Forensic Med Pathol 1985; 6: 2I-24.

33. Rogde S, Hougen HP, Poulsen K. Asphyxial homicide in two scandinavian capitals. Am J Forensic Med Pathol 200I; 22: I28-I33.

34. Press E, Walker J, Crawford I. An interstate drowning study. Amer J Pub Health 1968; 58: 2275-2289.

35. Wirthwein DP, Barnard J], Prahlow JA. Suicide by drowning. A 20 year review. J Forensic Sci 2002; 47: I3I-I36.

36. Wintemute GJ, Kraus JF, Teret SP, Wright M. Drowning in childhood and adolescence: A population based study. Amer J Pub Health 1987; 77: 830-832.

37. Gamero J], Romero JL, Arufe MI, Vizcaya MA, Balanza E. A study among the population of Sevilla of death due to submersion. Amer J Forensic Med Pathol 1997; 18: 70-74.

38. Lucas J, Goldfeder LB, Gill JR. Bodies found in the waterways of New York City. J Forensic Sci 2002; 47: 137-14I.

39. Auer A. Suicide by drowning in Uusimaa province in Southern Finland. Med Sci Law 1990; 30: 175-179.

40. Brouardel P, Vibert Ch. Etude sur la submersion. Ann Hyg Publ Méd Légale 1880; 4: 452-470.

4I. Brouardel P, Loye P. Recherches expérimentales sur la mort par submersion brusque. Masson Edit. Paris. 1889.

42. Orlowski JP, Abulleil MM, Phillips JM. The hemodynamic and cardiovascular effects of near-drowning in hypotonic, isotonic or hypertonic solutions. Ann Emerg Med 1989; 18: 1044-1049.

43. Modell JH. Drowning. New Eng J Med 1993; 328: 253-256.

44. Noble CS, Sharpe N. Drowning: its mechanism and treatment. Can Med Assoc ] 1963; 89: 402-405.

45. Hasibeder WR. Drowning. Curr Opin Anaesthesiol 2003; 16: 139-146.

46. Durigon M. Pathologie médico-légale. Masson Edit. Paris. 1988. 47. Adelson L. The Pathology of Homicide. Charles C Thomas Publ. Springfield. 1974.

48. Chiodi V, Gilli R, Puccini C, Portigliatti-Barbos M, Fallani M, De Bernardi A. Manuale di Medicina Legale. Casa Ed. Dr. F Vallardi. Milano. 1978.

49. Zangani P, Palmieri VM, Sciaudone. Manuale di Medicina Legale e delle Assicurazioni. Morano Editore. Napoli. 30 ed. 1985.

50. Modell JH, Moya F. Effects of volume of aspirated fluid during chlorinated fresh water drowning. Anesthesiology 1966; 27: 662-672.

5I. Harries MG. Drowning in man. Crit Care Med 1981; 9: 407408.

52. Swann HG, Brucer M, Moore C, Vezien BL. Fresh water and sea water drowning: A study of terminal cardiac and biochemical events. Tex Rep Biol Med 1947; 5: 423-437. 
53. Swann HG, Spallford NR. Body salt and water changes during fresh water and seawater drowning. Tex Rep Biol Med 1951; 9:356-382.

54. Modell JH, Gaub M, Moya F, Vestal B, Swarz H. Physiologic effects of near-drowning with chlorinated fresh water, distilled water and isotonic saline. Anesthesiology 1966; 27: 33-4I.

55. Fleetham JA, Munt PW. Near-drowning in Canadian waters. Can Med Assoc J 1978; II8: 914-917.

56. Modell JH, Davis JH, Giammona ST et al. Blood changes in human near-drowning victims. JAMA 1968; 203: 337-343.

57. Hasan S, Avery WG, Fabian C et al. Near-drowning in humans. A report of 32 patients. Chest 1971; 59: 191-197.

58. Lawler W. Bodies recovered from water: A personal approach and consideration of difficulties. J Clin Pathol 1992; 45:654-659.

59. Giammona ST, Modell JH. Drowning by total inmersion: effects on pulmonary surfactant of destilled water, isotonic saline and sea water. Am J Dis Child 1967; I14: 612-616.

60. Modell JH, Graves SA, Ketover A. Clinical course of 9I consecutive near-drowning victims. Chest 1976; 70: 231-238.

61. Orlowski JP. Drowning, near-drowning and ice-water submersion. Pediatr Clin North Am 1987; 34: 75-91.

62. Ellis RJ. Severe hypernatremia from sea water ingestion during near-drowning in a Hurricane. West J Med 1997; 167: 430-433.

63. Fuller RH. The clinical pathology of human near-drowning. Proc R Soc Med 1963; 56: 33-38.

64. Modell JH. Serum electrolyte changes in near-drowning victims. JAMA 1985; 253: 557.

65. Pearn J. Pathophysiology of drowning. Med J Aust 1985; 142: 586-560.

66. Bierens J], Knape JT, Gelissen HP. Drowning. Curr Opin Crit Care 2002; 8: 578-586.

67. Ibsen LM, Koch T. Submersion and asphyxial injury. Crit Care Med 2002; 30: S402-S408.

68. Olshaker JS. Near drowning. Emerg Med Clin N Am 1992; 10: 339-350.

69. Conn AW, Katsuyuki M, Katayama M et al. A canine study of cold water drowning in fresh versus salt water. Crit Care Med 1995; 23: 2029-2037.

70. Modell JH, Bellefleur M, Davis JH. Drowning without aspiration: Is this an appropriate diagnosis? J Forensic Sci 1999; 44: III9-II23. 71. Moar J]. Drowning. Postmortem appearances and forensic significance. A case report. S Afr Med J 1983; 64: 792-795.

72. Shaw KN, Briede CA. Submersion injuries: drowning and neardrowning. Emerg Med Clin N Am 1989; 7: 355-370.

73. Shkrum MJ, Ramsay DA. Forensic Pathology of Trauma. Humana Press. Totowa. 2007. 243-293.

74. Lunetta P, Modell JP. Macroscopical, microscopical and laboratory findings in drowning victims. In: M Tsokos (Ed), Forensic Pathology Reviews, vol 3. Humana Press. Totowa. 2005. Págs. 3-77. 75. Lunetta P, Modell JH, Sajantila A. What is the incidence and significance of "dry-lungs" in bodies found in water? Am J Forensic Med Pathol 2004; 25: 29I-301.
76. Craig AB. Causes of loss of consciousness during underwater swimming. J Appl Physiol 1961; 16: 583-586.

77. Longheed DW, Janes JM, Hall GE. Physiological studies in experimental asphyxia and drowning. Can Med Assoc J 1939; 40: 423428.

78. Spilsbury B. Some medico-legal aspects of shock. Medico-Legal and Criminological Review 1934; 2: I-13.

79. Simpson K. Deaths from vagal inhibition. Lancet 1949; I: 558-560. 80. Gardner E. Mechanism of certain forms of sudden death in medico-legal practice. Medico-Legal and criminological Review 1942; 10: 120-133.

81. Steinman AM. Cardiopulmonary resuscitation and hypothermia. Circulation 1986; 74: 29-32.

82. Wollenek G, Honarwar N, Golej J, Marx M. Cold water submersion and cardiac arrest in treatment of severe hypothermia with cardiopulmonary bypass. Resuscitation 2002; 52: 255-263.

83. Keatinge WR, Hayward MH. Sudden death in cold water and ventricular arrhytmia. J Forensic Sci 1981; 26: 459-461.

84. Ackerman MJ, Tester DJ, porter CJ. Swimming a genespecific arrhythmogenic trigger for inherited log QT syndrome. Mayo Clin Proc 1999; 74: 1088-1094.

85. Ackerman MJ, Tester DJ, Porter CJ, Edwards WD. Molecular diagnosis of the inherited long-QT syndrome in a women who died after near-drowning. N EngI ] Med 1999; 34I: II2I-II25.

86. Lunetta P, Levo A, Laitinen PJ, Fodstad H, Kontula K, Sajantila A. Molecular screening of selected lon QT syndrome (LQTS) mutations in 165 consecutive bodies found in water. Int J Legal Med 2003; II7: II5-II7.

87. Choi G, Kopplin LJ, Tester DJ, Will ML, Haglund CM, Ackerman MJ. Spectrum and frequency of cardiac channel defects in swimming-triggered arrhythmia syndromes. Circulation 2004; II0: 2119-2124.

88. Parikh CK. Parikh's Text Book of Medical Jurisprudence and Toxicology. Medical Publ Bombay. 1979.

89. De Bernardi A, Marras G, Turletti M, Lubinu F, Sini MG. Elementi di Patologia Medico Legale. A Delfino Edit. Roma. 1981.

90. Gordon I, Shapiro HA, Berson SD. Forensic Medicine. A Guide to Principles. Churchill Livingstone. Edinburgh. Third ed. 1988.

91. Knight B. Forensic Pathology. Arnold. London. Second ed. 1996. 92. Trezza FC. Lesionología y Patología Forense. In: JA Patitó, OA Lossetti, FC Trezza, C Guzman, NR Stingo (eds). Tratado de Medicina Legal y Elementos de Patología Forense. Edit Quorum. Buenos Aires. 2003.

93. Bell MD. Drowning. In: D Dolinak, EW Matshes, EO Lew (eds), Forensic Pathology. Principles and Practice. Elsevier Academic Press. London. 2005.

94. Piette MHA, De Letter EA. Drowning: still a difficult autopsy diagnosis. Forensic Sci Int 2006; 163: I-9.

95. Lunetta P, Penttilä A, Sajantila A. Circumstances and macropathologic findings in 1590 consecutive cases of bodies found in water. Am J Forensic Med Pathol 2002; 23: 37I-376. 
96. Giertsen JC. Drowning. In: CG Tedeschi, WG Eckert, LG Tedeschi (eds), Forensic Medicine. WB Saunders Co Philadelphia. 1977. I317-I333.

97. Carter N, Ali F, Green MA. Problems in the interpretation of hemorrhage into neck musculature in cases of drowning. Am J Forensic Med Pathol 1998; 19: 223-225.

98. Püschel K, Schulz F, Darrmann I, Tsokos M. Macromorphology and histology of intramuscular haemorrhages in cases of drowning. Int J Legal Med 1999; II2: 101-106.

99. Keil W, Kondo T, Beer GM. Haemorrhages in the posterior cricoarytenoid muscles. An unspecific autopsy findings. Forensic Sci Int 1998; 95: 225-230.

100. De La Grandmaison GL, Clairand I, Durigon M. Organ weight in 684 adult autopsies: New tables for a caucasoid population. Forensic Sci Int 2001; II9: I49-I54.

IOI. Copeland AR. An assessment of lung weights in drowning cases. The Metro Dade County experience from 1978 to 1982. Am J Forensic Med Pathol 1985; 6: 301-304.

102. Hadley JA, Fowler DR. Erratum to "Organ weight effects of drowning and asphyxiation on the lungs, liver, brain, heart, kidneys and spleen". Forensic Sci Int 2003; 137: 239-246.

103. Yorulmaz C, Arican N, Afacan I, Dokgoz H, Asirdizer M. Pleural effusion in bodies recovered from water. Forensic Sci Int 2003; 136: |6-2|.

104. Terazawa K, Haga K. The role of pleural effusion in drowning. Am J Forensic Med Pathol 1996; 17: 173-174.

105. Morild I. Pleural effusion in drowning. Am J Forensic Med Pathol 1995; I6: 253-256.

106. Zhu BL, Quan L, Li DR, Taniguchi M, Kamikodai Y, Tsuda K, Fujita MQ, Nishi K, Tsuji T, Maeda H. Postmortem lung weight in drownings: A comparison with acute asphyxiation and cardiac death. Legal Medicine 2003; 5: 20-26.

107. Inoue H, Ishida T, Tsuji A, Kudo K, Ikeda N. Electrolyte analysis in pleural effusion as an indicator of the drowning medium. Legal Medicine 2005: 7: 96-102.

108. Reh H. Diagnostik des Ertrinkungstodes und Bestimmung der Wasserzeit. M Triltsch Verlag. Düsseldorf. 1970.

109. Blanco J, García SA, Tamayo NM, Hinojal R. Gastric mucosa lesions in drowning: its usefulness in Forensic Pathology. Legal Medicine 2005; 7: 89-95.

II0. Haffner HT, Graw M, Erdelkamp J. Spleen findings in drowning. Forensic Sci Int 1994; 66: 95-104.

III. Nishitani Y, Fujii K, Okazaki S, Imabayashi K, Matsumoto H. Weight ratio of the lungs and pleural effusion to the spleen in the diagnosis of drowning. Legal Medicine 2006; 8: 22-27.

II2. Niles NR. Hemorrhage in the middle-ear and mastoid in drowning. Am J Clin Pathol 1963; 40: 28I-283.

II3. Ito Y, Kimura H. Histological examination of the temporal bone in medicolegal cases of asphyxia. Forensic Sci Int 1990; I4: I35-I42. II4. Jeanmonod R, Staub CH, Mermillod B. The reliability of cardiac haemodilution as a diagnostic test of drowning. Forensic Sci Int 1992; 52: 171-180.
II5. Byard RW, Cains G, Simpson E, Eitzen D, Tsokos M. Drowning, haemodilution, haemolysis and staining of the intima of the aortic root. Preliminary observations. J Clin Forensic Med 2006; I3: I2I124.

I16. Hotmar P. Nachweis von Flüssigkeit in den Nasennebenhöhlen als mögliches diagnostisches Zeichen des Ertrinkungstodes. Arch Criminol 1996; 198: 89-94.

II7. Bohnert M, Ropohl D, Pollak S. Zur rechtsmedizinischen Bedeutung des Flüssigkeitsgehaltes in den keilbeinhöhlen. Arch Criminol 2002; 209: 158-164.

II8. Navarro JA, Villavieja L, Serrat D, Castellano M. L'examen radiologique et arteriographique cranien dans la mort par noyade. J Méd Lég Droit Méd 1988; 3I: 247.

119. Gresham GA. Atlas de Medicina Forense. Edit CientíficoMédica. Barcelona. 1977.

I20. Polson CJ, Gee DJ, Knight B. The essentials of forensic medicine. Pergamon Press. Oxford. 4th ed. 1985.

I2I. Byard RW, Cains GE, Gilbert JD. Is haemolytic staining of the aortic root a sign of fresh water drowning? Pathology 2005; 37: 551-552.

I22. Dérobert L. Médecine Légale. Flammarion Médecine-Sciences. Paris. 1974.

I23. Janssen W. Forensic Histopathology. Springer Verlag. Berlin. 1984.

124. Brinkmann B, Fechner G, Püschel K. Zur Lungenhistologie bei experimentellen Ertrinken. Z Rechtsmed 1983; 89: 267-277.

I25. Brinkmann B, Fechner G, Püschel K. Zur ultrastrukturpathologie des Alveolarapparates beim experimentellen Ertrinken. Z Rechtsmed 1983; 91: 47-60.

126. Morita M, Tabata N, Maya A. Studies on asphyxia: On the changes of the alveolar walls of rats in the hypoxic state. Forensic Sci Int 1985; 27: 81-92.

I27. Locali RF, De Almeida M, De Oliveira IS. Use of the histopathology in the differential diagnosis of drowning in fresh and salty water: An experimental model establishment in rats. Acta Cirur Bras 2006; 21: 203-206.

I28. Fornes P, Pepin G, Heudes H, Lecomte D. Diagnosis of drowning by combined computer-assisted histomorphometry of lungs with blood strontium determination. J Forensic Sci 1998; 43: 772-776. I29. Betz P, Nerlich A, Penning R, Eisenmenger W. Alveolar macrophages and the diagnosis of drowning. Forensic Sci Int 1993; 62: 217-224.

130. Karkola K, Neittaanmaki H. Diagnosis of drowning by investigation of left heart blood. Forensic Sci Int 1981; 18: 149-153.

13I. Delmonte C, Capelozzi VL. Morphologic determinants of asphyxia in lungs. A semiquantitative study in forensic autopsies. Am J Forensic Med Pathol 200I; 22: 139-149.

132. Reidbord HE, Spitz WU. Ultrastructural alterations in rat lungs: Changes after intratracheal perfusion with freshwater and seawater. Arch Pathol 1966; 81: 103-107.

133. Nopanitaya W, Gambill TG, Brinkhous KM. Freshwater drowning. Arch Pathol 1974; 98: 361. 
134. Torre C, Varetto L, Tappi E. Scanning electron microscopic ultrastructural alterations of the pulmonary alveolus in experimental drowning. J Forensic Sci 1983; 28: 1008-1012.

135. Miller FN. Peery and Miller's Pathology. Little Brown and Co. Boston. Third ed. 1978.

136. Torre C, Varetto L. Scanning electron microscope study of the lung in drowning. J Forensic Sci 1985; 30: 456-46l.

137. Saukko P, Knight B. Knight's Forensic Pathology. Arnold. London. 2004.

138. Vimercati F, Colonna M, Altamura BM, Di Nunno C, GaglianoCandela R. Aspetti isto-enzimatici del miocardio nell ' annegamento sperimentale. Zacchia 1976; 5I: 433-44I.

139. Gagliano-Candela R, Colonna M, Vimercati F, Altamura BM, Barulli F. Le attività transaminasiche e della creatin-fosfo-chinasi del siero nell ' annegamento sperimentale in soluzione fisiologica. Zacchia 1977; 52: 41-50.

140. Carrara M. Untersuchungen über den osmotischen druck und die specifische elektrisches leitfähigkeit des blutes bei der fäulnis. Vierteljahrsschr Gerichtl Med 1902; 24: 236.

141. Placzek M. Die Blutdichte als Zeichen des Ertrinkungsvorganges. Vierteljahrsschr Gerichtl Med 1903; $25: 3$.

142. Gettler A0. A method for the determination of death by drowning. JAMA 1921; 77: 1650-1652.

143. Durlacher S, Freimuth HC, Swann HE. Blood changes in man following death due to drowning, with comments on test for drowning. Arch Pathol 1953; 56: 454-46l.

144. Moritz AR. Chemical methods for the determination of death by drowning. Physiol Rev 1944; 24:70-88.

145. Freimuth HC, Swann HE. Plasma specific gravity changes in sudden deaths. Arch Pathol 1955; 59: 214-218.

146. Rivers J, Orr G, Lee H. Electrolytes in near-drowning. Br Med J 1970; ii: 157-160.

147. Modell JH, Davis JH. Electrolyte changes in human drowning victims. Anesthesiology 1969; 30: 414.

148. Lorente JA, Hernández Cueto C, Villanueva E. Utilidad de los parámetros hematológicos métrico-ponderales e iónicos en el diagnóstico de la sumersión vital. Riv Ital Med Legale 1990; 12: 803-8II. 149. Yu-Chuan C, Zhao-Ke D, Jia-Zhen Z. The significance of detecting serum fluorine level in the diagnosis of drowning. Forensic Sci Int 1990; 46: 287-292.

150. Zhu BL, Ishida K, Taniguchi M, Quan L, Oritani S, Tsuda K, Kamikodai Y, Fujita MQ, Maeda H. Possible postmortem serum markers for differentiation between fresh, saltwater drowning and acute cardiac death: A preliminary investigation. Legal Medicine 2003; 5: S298-S30I.

I5I. Zhu BL, Ishikawa T, Quan L, Li DR, Zhao D, Michiue T, Maeda H. Evaluation of postmortem serum calcium and magnesium levels in relation to the causes of death in forensic autopsy. Forensic Sci Int 2005; 155: 18-23.

152. Zhu BL, Ishikawa T, Michiue T, Li DR, Zhao D, Oritani S, Kamikodai Y, Tsuda K, Okazaki S, Maeda H. Postmortem cardiac tro- ponin T levels in the blood and pericardial fluid. Part I. Analysis with special regard to traumatic causes of death. Legal Medicine 2006; 8: 86-93.

I53. Zhu BL, Ishikawa T, Michiue T, Tanaka S, Zhao D, Li DR, Quan L, Oritani S, Maeda H. Differences in postmortem urea nitrogen, creatinine and uric acid levels between blood and pericardial fluid in acute death. Legal Medicine 2007; 9: II5-I22.

I54. De La Grandmaison GL, Leterreux M, Lasseuguette K, Alvarez JC, De Mazancourt Ph, Durigon M. Study of the diagnostic value of iron in fresh water drowning. Forensic Sci Int 2006; 157: II7-120. 155. Icard S. La preuve de la mort par submersion suivant qu 'elle a eu lieu dans une rivière ou dans la mer. Rev Pathol Comparée Hyg Gen 1932; 32: 559-571.

156. Abdallah AM, Hassan SA, Kabil MA, Ghanim AEE. Serum strontium estimation as a diagnostic criterion of the type of drowning water. Forensic Sci Int 1985; 28: 47-52.

157. Piette M, Timperman J, Parisis N. Serum strontium estimation as a medico-legal diagnostic indicator of drowning. Med Sci Law 1989; 29: 162-171.

158. Piette M. Strontium as a marker for drowning: When is it useful? Police Surgeon 1992; 42: 17-18.

159. Piette M, Desmet B, Dams R. Determination of strontium in human whole blood by ICP-AES. Sci Total Environ 1994; I41: 269-273.

160. Piette M. La noyade: Recherches actuelles. J Méd Lég Droit Méd 1996; 39: 417-420.

I6I. Azparren J, De la Rosa I, Sancho M. Biventricular measurement of blood strontium in real cases of drowning. Forensic Sci Int 1994; 69: 139-148.

162. Azparren JE, Vallejo G, Reyes E, Herranz A, Sancho M. Study of the diagnostic value of strontium, chloride, haemoglobin and diatoms in inmersion cases. Forensic Sci Int 1998; 91: 123-132.

163. Azparren JE, Ortega A, Bueno H, Andreu M. Blood strontium concentration related to the length of the agonal period in seawater drowning cases. Forensic Sci Int 2000; 108: 51-60.

164. Azparren JE, Fernández-Rodríguez A, Vallejo G. Diagnosing death by drowning in fresh water using blood strontium as an indicator. Forensic Sci Int 2003; 137: 55-59.

165. Azparren JE, Perucha E, Martínez P, Muñoz R, Vallejo G. Factors affecting strontium absorption in drowning. Forensic Sci Int 2006 (in press). I66. Azparren JE, Cubero C, Perucha E, Martínez P, Vallejo G. Comparison between lung weight and blood strontium in bodies found in seawater. Forensic Sci Int 2006 (in press).

167. Pérez-Cárceles MD, Vizcaya MA, Sibón A, Gil ML, Osuna E, Falcón M, Romero JL, Luna A. Blood strontium levels in different causes of death. Comunicación presentada al XXth Congress of International Academy of Legal Medicine. Budapest (Hungría). 2006.

168. Pérez-Cárceles MD, Martínez P, Vizcaya MA, Gil ML, Casas MT, Osuna E, Luna A. Levels of strontium and surfactant protein A (SPA) in different causes of death. A preliminary study. Comunicación presentada al 17th Meeting of the International Association of Forensic Sciences. Hong Kong (China). 2005. 
169. Bajanowski T, Brinkmann B, Stefanec AM, Barckhaus RH, Fechner $G$. Detection and analysis of tracers in experimental drowning. Int J Legal Med 1998; III: 57-6I.

170. Corin G, Stockis E. Le diagnostic médico-légale de I'asphyxie par submersion. Ann Soc Méd Légale Belg 1909; 20: 14-23.

171. Corin G. A propos du diagnostic de la mort par submersion. Ann Soc Méd Légale Belg 1909; 20: 375-377.

172. Stockis E. Le diagnostic de la mort par submersion par la méthode du plancton cristallin. Ann Méd Légale Crim Polic Sci 1921; I: 43-48.

173. Revenstorf V. Der Nachweis der aspirierten Ertränkungsflüssigkeit als Kriterium des Todes durch Ertrinken. Vjschr Gerichtl Med 1904; 27: 274-299.

174. Ludes B, Coste M. Diatomées et Médecine Légale. Applications de la recherche des Diatomées au diagnostic de la submersion vitale. Édit Médicales Internationales. Paris. 1996.

175. Pollanen MS. Forensic diatomology and drowning. Elsevier. Amsterdam. 1998.

176. Ludes B, Coste M, North N, Doray S, Tracqui A, Kintz P. Diatom analysis in victim 's tissues as an indicator of the site of drowning. Int J Legal Med 1999; II2: 163-166.

177. Hürlimann J, Feer P, Elber F, Niederberger K, Dirnhofer R, Wyler D. Diatom detection in the diagnosis of death by drowning. Int J Legal Med 2000; II4: 6-14.

178. Timperman J. Medico-legal problems in death by drowning. Its diagnosis by the diatom method. J Forensic Sci 1969; 16: 45-75.

179. Hendey NI. The diagnostic value of diatoms in drowning. Med Sci Law 1973; 13: 23-34.

180. Peabody AJ. Diatoms and drowning. A review. Med Sci Law 1980; 20; 254-261.

181. Foged N. Diatoms and drowning. Once more. Forensic Sci Int 1983; 21: 153-159.

182. Pollanen MS. Diatoms and homicide. Forensic Sci Int 1998; 91: 29-34.

183. Pollanen MS, Cheung C, Chiasson DA. The diagnostic value of the diatom test for drowning. I. Utility: A retrospective analysis of $77 \mathrm{I}$ cases of drowning in Ontario, Can. J Forensic Sci 1997; 42: 28I-285.

184. Pollanen MS. The diagnostic value of the diatom test for drowning. II. Validity: Analysis of diatoms in bone marrow and drowning medium. J Forensic Sci 1997; 42: 286-290.

185. Funayama M, Mimasaka S, Nata M, Hashiyada M, Yajima Y. Diatom numbers around the continental shelf break. Am J Forensic Med Pathol 200I; 22: 236-238.

186. Tomonaga T. Identification of death by drowning by the disorganization methods (diatom methods). Acta Med Nagasaki 1960; 5: II6-125.

187. Nanikawa R, Kotoku S. Medicolegal observation on a dead body draw up from the sea bed, with special reference to ethanol and diatoms. Forensic Sci 1974; 3: 225-232.

188. Neidhart DA, Greendyke RM. The significance of diatom demonstration in the diagnosis of death by drowning. Am J Clin
Pathol 1967; 48: 377-382.

189. Timperman J. The diagnosis of drowning. A review. Forensic Sci 1972; I: 397-409.

190. Auer A, Möttönen M. Diatoms and drowning. $Z$ Rechtsmed 1988; I0I: 87-98.

191. Lunetta P, Penttilä A, Hällfors G. Scanning and transmission electron microscopical evidence of the capacity of diatoms to penetrate the alveolo-capilary barrier in drowning. Int J Legal Med 1998; III: 229-237.

192. Devos C, Timperman J, Piette M. Deaths in the bath. Med Sci Law 1985; 25: 189-200.

193. Auer A. Qualitative diatom analysis as a tool to diagnose drowning. Am J Forensic Med Pathol I99I; I2: 213-218.

194. Fukui Y, Hata M, Takahashi S, Matsubara K. A new method for detecting diatoms in human organs. Forensic Sci Int 1980; 16: 67-74.

195. Sidari L, Di Nunno N, Costantinides F, Melato M. Diatom test with Soluene-350 to diagnose drowning in sea water. Forensic Sci Int 1999; 103: 61-65.

196. Kobayashi M, Yamada Y, Zhang WD, Itakura Y, Nagao M, Takatori T. Novel detection of plankton from lung tissue by enzymatic digestion method. Forensic Sci Int 1993; 60: 81-90.

197. Kane M, Fukunaga T, Maeda H, Nishi K. The detection of picoplankton I6S rDNA in cases of drowning. Int J Legal Med 1996; 108: 323-326.

198. Abe S, Suto M, Nakamura H, Gunji H, Hiraiwa K, Suzuki T, Itoh T, Kochi H, Hoshiai GI. A novel PCR method for identifying plankton in cases of death by drowning. Med Sci Law 2003; 43: 23-30.

199. Suto M, Abe S, Nakamura H, Suzuki T, Itoh T, Kochi H, Hoshiai $\mathrm{GI}$, Hiraiwa K. Phytoplankton gene detection in drowned rabbits. Legal Medicine 2003; 5: SI42-SI44.

200. Taylor J]. Diatoms and drowning. A cautionary case note. Med Sci Law 1994; 34: 78-79.

20I. Peabody AJ, Burgess RM. Diatoms and Drowning. III. Diatoms in the organs of drowned subjects. CRE Report. Central Research Establishment, Home Office Forensic Science Service. Aldennaston. 1985.

202. Chardez D, Lambert J. Protozoaires ciliés et Thatatologie. Forensic Sci Int 1985; 28: 83-101.

203. Yoshimura S, Yoshida M, Okii Y, Tokiyasu T, Watabiki T, Akane A. Detection of green algae (Chlorophyceae) for the diagnosis of drowning. Int J Legal Med 1995; 108: 39-42.

204. Jianping Q, Enshou W. A study on the diagnosis of drowning by examination of lung chlorophyll (a) of planktons with a spectrofluorophotometer. Forensic Sci Int 1992; 53: 149-155.

205. Casamatta DA, Verb RG. Algal colonization of submerged carcasses in a Mid-Order Woodland Stream. J Forensic Sci 2000; 45: I280-1285.

206. Haefner JN, Wallace JR, Merritt RW. Pig decomposition in lotic aquatic systems: The potential use of algal growth in establishing a postmortem submersion interval (PMSI). J Forensic Sci 2004; 49: 330-336. 
207. Mishul' skii AM. The use of bacteriological analysis of the blood in the diagnosis of death by drowning (Russ). Sud Med Ekspert 1990; 33: 26-28.

208. Lucci A, Cirnelli A. A microbiological test for the diagnosis of death by drowning. Forensic Sci Int 2007: 168: 34-36.

209. Reiter C. Zum Nachweis des Ertrinkungstodes mittels ins Herzblut eingeschwemmter Raucherzellen. Z Rechtsmed 1984; 93: 79-88.

210. Lorente JA, Hernández-Cueto C, Villanueva E, Luna JD. The usefulness of lung surfactant phospholipids (LSPS) in the diagnosis of drowning. J Forensic Sci 1990; 35: I367-I372.

2II. Lorente JA, Lorente M, Villanueva E. Postmortem stability of lung surfactant phospholipids. J Forensic Sci 1992; 37: I34I-I345.

2I2. Kamada S, Seo Y, Takahama K. A sandwich enzyme immunoassay for pulmonary surfactant protein $D$ and measurement of its blood levels in drowning victims. Forensic Sci Int 2000; 109: 51-63. 213. Zhu BL, Ishida K, Quan L, Fujita MQ, Maeda H. Immunohistochemistry of pulmonary surfactant apoprotein A in forensic autopsy: reassessment in relation to the causes of death. Foresic Sci Int 2000; II3: 193-197.

214. Zhu BL, Ishida K, Quan L, Li DR, Taniguchi M, Fujita MQ, Maeda H, Tsuji T. Pulmonary immunohistochemistry and serum levels of a surfactant-associated protein $A$ in fatal drowning. Legal Medicine 2002; 4: I-6.

215. Ishida K, Zhu BL, Maeda H. A quantitative RT-PCR assay of surfactant-associated protein Al and A2 mRNA transcripts as a dignostic tool for acute asphyxial death. Legal Medicine 2002; 4: 7-I2.

216. Maeda H, Fujita MQ, Zhu BL, Ishida K, Quan L, Oritani S, Taniguchi M. Pulmonary surfactant-associated protein $A$ as a marker of respiratory distress in forensic pathology: assessment of the immunohistochemical and biochemical findings. Legal Medicine 2003; 5, Supl I: S318-S32I.

217. Anderson JV, Millar ND, $0=$ Hare JP et al. Atrial natriuretic peptide: Physiological release associated with natriuresis during water immersion in man. Clinical Science 1986; 73: 319-322.

218. Lorente Acosta JA. Estudio crítico del diagnóstico bioquímico de la sumersión vital. A propósito de dos nuevos marcadores: El Péptido Natriurético Auricular y los componentes fosfolipídicos del surfactante pulmonar. Tesis Doctoral. Universidad de Granada. 1989.
219. Lorente JA, Hernández-Cueto C, Villanueva E. Postmortem stability of the rat atrial natriuretic peptide in blood and atrial tissue. Rev Esp Fisiol 1989; 45: 127-130.

220. Zhu BL, Ishikawa T, Michiue T, Li DR, Zhao D, Tanaka S, Kamikodai Y, Tsuda K, Okazaki S, Maeda H. Postmortem pericardial natriuretic peptides as markers of cardiac function in medico-legal autopsies. Int J Legal Med 2007; I2I: 28-35.

22I. Quan L, Zhu BL, Ishida K, Oritani S, Taniguchi M, Fujita MQ, Maeda H. Intranuclear ubiquitin immunoreactivity of the pigmented neurons of the substantia nigra in fatal acute mechanical asphyxiation and drowning. Int J Legal Med 200I; II5: 6-II.

222. Lehmann K, Beuthin A. Der Nachweis von Calciumlignosulfonat im Blut und in den Organpreßsäften ertränkter Ratten als Zeichen vitalen Ertrinkens. Z Rechtsmed 1971; 68: II-I6.

223. Mukaida M, Kimura H, Takada Y. Detection of bathsalts in the lung of a baby drowned in a bathtub: A case report. Forensic Sci Int 1998; 93: 5-II.

224. López Gómez L, Gisbert Calabuig JA. Tratado de Medicina Legal. Ed Saber, Valencia. 30 ed. Tomo I. 1970.

225. Reh H. In: B Müller (ed), Gerichtliche Medizin. Springer, Berlin. 1975.

226. Mason JK, Purdue BN. The Pathology of Trauma. Arnold, London. 30 ed. 2000.

227. Bray M. Chemical estimation of fresh water immersion intervals. Am J Forensic Med Pathol 1985; 6: I33-139.

228. Haskell NH, McShaffrey DG, Hawley DA, Williams RE, Pless JE. Use of aquatic insects in determining submersion interval. J Forensic Sci 1989; 34: 622-632.

229. Keiper JB, Chapman EG, Foote BA. Midge larvae (Diptera: Chironomidae) as indicators of postmortem submersion interval of carcasses in a Wooland Strem: A preliminary report. J Forensic Sci 1997; 42: 1074-1079.

230. Hobischak NR, Anderson GS. Time of submergence using Aquatic Invertebrate Succession and Decompositional changes. J Forensic Sci 2002; 47: I42-I5I. 